\title{
Review
}

\section{Modelling the impacts of marine protected areas for mobile exploited fish populations and their fisheries: what we recently learnt and where we should be going}

\author{
Arnaud GRÜSS ${ }^{1,2,3, a}$ \\ ${ }^{1}$ Institut de Recherche pour le Développement (IRD), UMR EME 212 (IRD/Ifremer/Université Montpellier 2), Centre de Recherche \\ Halieutique Méditerranéenne et Tropicale, avenue Jean Monnet, CS30171, 34203 Sète Cedex, France \\ 2 Cooperative Institute for Marine and Atmospheric Studies, Rosenstiel School of Marine and Atmospheric Science, University of Miami, \\ 4600 Rickenbacker Causeway, Miami 33149, USA \\ 3 Southeast Fisheries Science Center, Sustainable Fisheries Division, 75 Virginia Beach Drive, Miami, FL 33149-1099, USA
}

Received 17 July 2014; Accepted 3 December 2014

\begin{abstract}
Marine protected areas (MPAs) are increasingly being considered and used for the management of fisheries targeting mobile fish populations. Here, the recent modelling literature on MPA effects for mobile fish populations and their fisheries is reviewed. Modelling studies conducted since 2011 have filled a considerable number of knowledge gaps on the impacts of MPAs for species exhibiting home-range behaviour, nomadic movements or behavioural polymorphism, and on the effects of "targeted MPAs", which aim to protect relatively small areas where migratory fishes spend an inordinate fraction of time or are highly vulnerable to fishing (e.g., nursery or spawning zones). Also, in recent years, two studies investigated the consequences of MPAs targeting highly migratory (tuna-like) fish populations for the first time in the history of MPA modelling. Recent modelling studies found that MPAs aimed at protecting mobile species may have positive conservation effects under a relatively wide range of situations, but may generate long-term fisheries benefits only under a very limited set of conditions. In particular, MPAs were not found to be beneficial for the fisheries targeting highly migratory populations. Strategies producing both conservation and fisheries benefits were identified, which depend on fish movement patterns and numerous aspects of fish life history and fisheries dynamics. However, in view of the diversity of fish movement patterns in MPA systems and current dynamics in resource management, it is clear that additional modelling work is needed to fully understand how protected areas affect mobile fish populations and their fisheries and to be able to implement pertinent MPAs. In particular, future modelling studies should systematically assess the effects of MPAs in relation to other management tools to find strategies that are most effective in meeting management objectives, and explore the impacts of "dynamic" MPAs that follow highly migratory fish populations in space and time.
\end{abstract}

Keywords: Marine protected areas / Marine reserves / Mobile fish populations / Modelling / Resource conservation / Fisheries yields / Migratory populations / Conservation targets

\section{Introduction}

Marine protected areas ("MPAs", hereafter also referred to as "closed areas"; see Glossary), zones where fishing and other extractive activities are partially or totally restricted yearround or seasonally, have become a mainstream management tool. The potential conservation benefits of MPAs are many, including the maintenance or recovery of fish spawning stock biomass (SSB) to levels that guarantee recruitment success, and a reduction of bycatch levels and of the damages that

a Corresponding author: agruss@rsmas .miami .edu fishing causes to marine habitats (Lubchenco et al. 2003; Bohnsack et al. 2004; Claudet 2011; Halpern 2014). Theoretical evolutionary studies have also shown that MPAs may mitigate fisheries-induced evolutionary changes in growth rate, size at maturation and other fish life-history traits (Baskett et al. 2005; Dunlop et al. 2009; Miethe et al. 2010). Moreover, MPAs have the capacity to enhance fish exploitable biomass and fisheries yields via the export of adult and juvenile biomass ("spillover") and eggs and larvae ("recruitment subsidy") to fished areas (Gell and Roberts 2003; Roberts 2012; Kerwath et al. 2013). Worldwide, the number of MPAs is increasing at 
a rapid pace so as to try to meet the conservation targets established for 2020 (i.e., 10\% of the world's ecological regions in MPAs; Convention on Biological Diversity (CBD) 2010; Wood 2011; Spalding et al. 2013; Halpern 2014). However, critical knowledge gaps and uncertainties remain on the impacts of MPAs, especially on their fisheries effects (Hilborn et al. 2004; Sale et al. 2005; Grüss et al. 2011a).

MPAs are likely to be ecologically and/or economically ineffective and may do more harm than good if they are inadequately designed or the consequences of their creation are poorly anticipated (Agardy et al. 2003, 2011; Kaiser 2005; Kaplan et al. 2010). Therefore, before moving too quickly towards conservation targets, a thorough and science-driven analysis of MPA impacts needs to take place (Sale et al. 2005; Kaplan et al. 2010; Edgar 2011; Chown 2013). General and applied modelling approaches have been increasingly employed in MPA research since the early 1990s (Guénette et al. 1998; Gerber et al. 2003; Botsford et al. 2009; Grüss et al. 2011a). Models are invaluable for providing rapid, detailed and relatively inexpensive insights into the potential effects of closed areas under alternate biological, ecological and management scenarios. They should be more widely used during the coming years to assess whether, and under what conditions, closed areas may improve species conservation and produce fisheries benefits in specific contexts (White et al. 2011; Grüss et al. 2014a; Rassweiler et al. 2014). One can distinguish between (1) biological MPA models, which typically analyse the effects of closed areas on species conservation, exploitable biomass (yield-per-recruit) and fisheries yields; and (2) bioeconomic MPA models, which primarily concentrate on the economic implications of closed areas (i.e., their impacts on fisheries costs and profits). In the present study, I chose to focus on the former type of models (hereafter simply referred to as "MPA models").

Until recently, MPA implementation has essentially concentrated in coastal and nearshore areas, where many fish populations are sedentary or have relatively low mobility (Roberts et al. 2005; Roberts 2007; Gaines et al. 2010). For this reason, modelling efforts have long been directed to evaluating the effects of the dispersal of eggs and larvae (hereafter simply referred to as "larval dispersal") on the functioning of MPAs (e.g., Tuck and Possingham 2000; Botsford et al. 2001; Gaines et al. 2003; Hastings and Botsford 2006), and the impacts of MPAs for populations dispersing exclusively in the larval phase and their fisheries (e.g., Sladek Nowlis and Roberts 1999; Stockhausen et al. 2000; Kahui and Alexander 2008; Kaplan et al. 2009). During the last seven to eight years, several large-scale MPAs have been established, including the Phoenix Islands and Cook Islands partial-take MPAs (Pacific Ocean), the Chagos Island no-take MPA (Indian Ocean) and the Coral Sea no-take MPA (Australia) (Pala 2009, 2010, 2013; Koldewey et al. 2010; Jones 2011; Barr and Possingham 2013; Singleton and Roberts 2014). Additional large-scale MPAs are going to be created during the coming years, including the Bermuda no-take MPA (Northwest Atlantic) and vast closed areas around Antarctica (Jones 2011; Brooks 2013; Pala 2013). These large-scale MPAs may offer protection to exploited fish populations exhibiting extensive movement, including some highly migratory populations (e.g., tropical tuna populations in the case of the Chagos Island no-take MPA; Koldewey et al. 2010). Moreover, closed areas primarily aimed at protecting migratory exploited species such as groupers forming transient spawning aggregations (Sadovy de Mitcheson and Colin 2012; Grüss et al. 2014a), hakes (Sink and Attwood 2008; Alemany et al. 2013), cods and haddocks (Murawski et al. 2005; Roberts and Mason 2008) and tunas and billfishes (Norse et al. 2005; Pala 2009, 2010) are increasingly being considered and used.

The aforementioned recent developments raise many questions regarding the impacts of MPAs for mobile exploited fish populations and their fisheries, which were reviewed in Grüss et al. (2011a). I conducted a search on the ISI Web of Science $e^{T M}$ and Google to identify the modelling studies that have tackled the issue of the conservation and fisheries effects of MPAs for mobile fish populations since Grüss et al. (2011a), i.e., during the last three-four years. This search revealed that recent MPA modelling efforts have essentially concentrated on four of the fundamental questions highlighted in Grüss et al. (2011a): (1) "How does adult and juvenile movement affect the conservation and fisheries effects of MPAs?"; (2) "Under what conditions may MPAs be beneficial both for the conservation of migratory exploited fish populations and for their fisheries without being extremely large?"; (3) "Can MPAs benefit highly migratory fish populations (i.e., populations moving over distances ranging from hundreds to thousands of kilometers; e.g., populations of tropical tunas and billfishes) and the fisheries targeting them?"; and (4) "To which extent does variability of movement in a particular life stage of a fish population impact MPA effects?".

In the present paper, I first review how the four fundamental questions identified above have been addressed in the modelling literature until recently (until 2011). Then, I report and discuss the findings of some recent published and unpublished modelling studies, which provide additional insights into these four fundamental questions. Finally, I identify issues that remain to be addressed with models to fully assess the impacts of MPAs for mobile exploited fish populations and the fisheries depending on them. Note that MPA models have usually explored the effects of no-take MPAs ("marine reserves") (Pelletier et al. 2009; White et al. 2011). Thus, the term "MPAs" hereafter refers to "year-round no-take MPAs", unless otherwise specified (e.g., "seasonal partial-take MPAs").

\section{What we knew until recently}

\subsection{How does adult and juvenile movement affect MPA effects?}

There exists a diversity of movement patterns exhibited by adult and juvenile fishes in MPA systems, as reviewed in Grüss et al. (2011a). In brief, adult and juvenile movement (hereafter often referred to as "fish movement") in MPA systems can either be "density-independent" (movement in a home range, nomadic movement, ontogenetic habitat shifts, and spawning migrations) or "density-dependent" (density-dependent spillover, density-dependent spill-in, and movements resulting from predator-prey interactions). The home range of a fish is the area that this fish uses for its normal activities (e.g., feeding, resting) during a part or all of its lifespan. Nomadic 


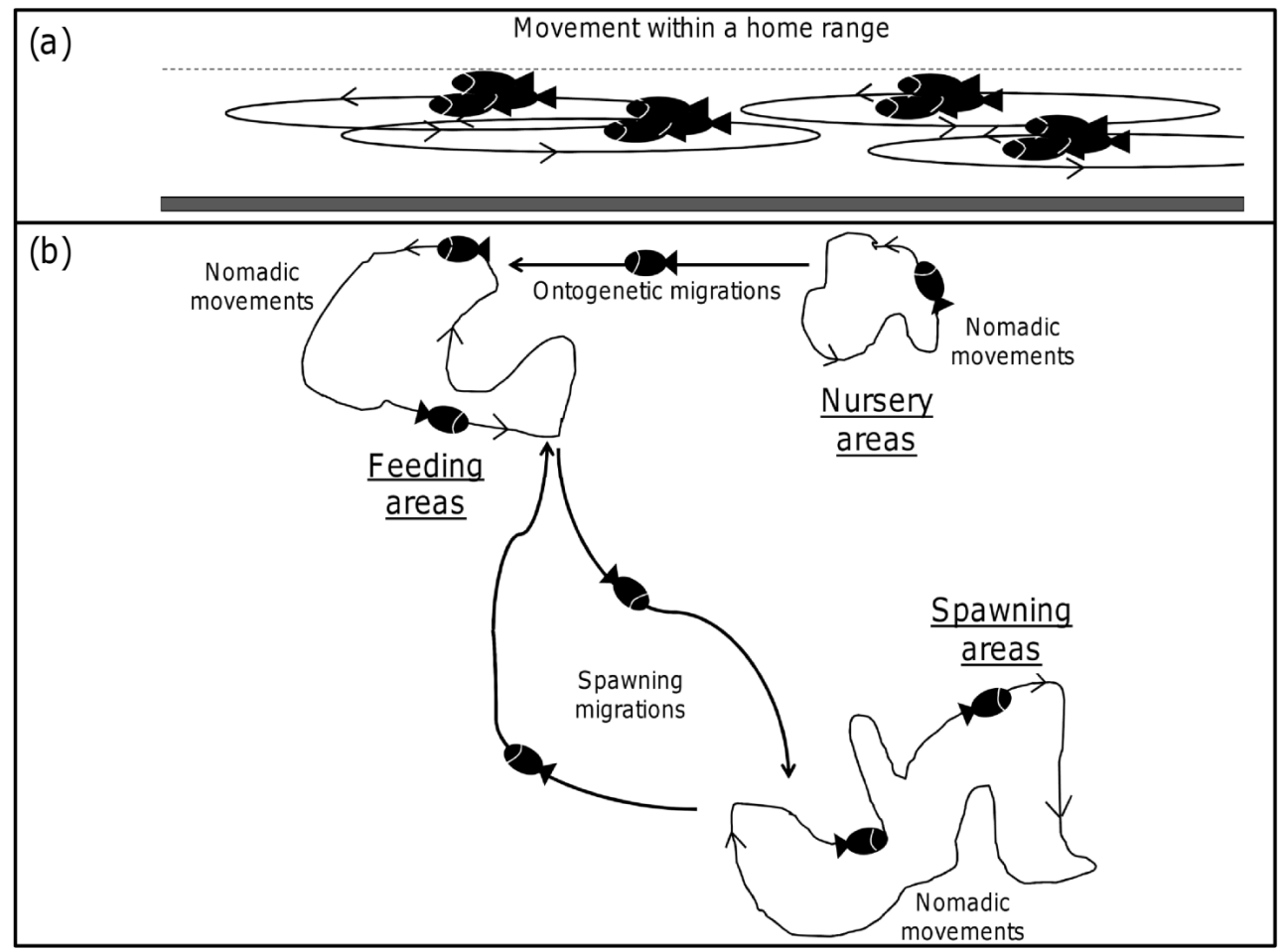

Fig. 1. Patterns of density-independent fish movement (home-range movement, nomadic movements, spawning migrations, ontogenetic migrations). (a) The home range of a fish is the area that this fish uses for its normal activities during a part or all of its lifespan. (b) Nomadic movement is relatively similar to movement within a home range and consists of long-distance displacements punctuated by small-scale displacements during foraging. Spawning migrations are seasonal movements between feeding (normal residence) areas and spawning areas. Ontogenetic migrations are a type of migration where fishes change habitats as they grow older. Within nursery, spawning and feeding areas, individuals of a migratory fish population move within a home range or undertake nomadic movements.

movement is relatively similar to movement within a home range and consists of long-distance displacements punctuated by small-scale displacements during foraging, whose direction and extent are often influenced by habitat quality. Spawning migrations are seasonal movements between feeding (normal residence) areas and spawning areas. Ontogenetic migrations ("ontogenetic habitat shifts") are a type of migrations where fishes change habitats as they grow older (see Grüss et al. (2011a) for a comprehensive review of fish movement patterns; Fig. 1).

In the past, MPA models often represented fish movement as a simple density-independent or density-dependent diffusion process across boundaries between closed and fished areas (e.g., Polacheck 1990; Holland and Brazee 1996; Guénette and Pitcher 1999; Rodwell and Roberts 2004). Other MPA models featured a more realistic representation of adult and juvenile movement (e.g., movement within a home range; Moffitt et al. 2009; adult migrations and ontogenetic habitat shifts; Holland 2000; Apostolaki et al. 2002; Gerber et al. 2005; Little et al. 2009; Table 1).

In the general modelling literature, it has long been established that fish movement can significantly reduce the conservation benefits of closed areas (e.g., increases in SSB, mitigation of fisheries-induced evolutionary changes in fish growth rate), since individuals moving between protected and nonprotected areas are effectively protected only for the percentage of time they spend inside MPAs (Gerber et al. 2005;
Miethe et al. 2010; Grüss et al. 2011a). General modelling studies also showed that, if enough habitat area is protected to ensure that supply of eggs and larvae would be at or near the carrying capacity of the modelled system in the absence of fish movement, moderate spillover can enhance fisheries yields without affecting population persistence (e.g., Guénette and Pitcher 1999; Stefansson and Rosenberg 2005; Moffitt et al. 2009; Le Quesne and Codling 2009). By contrast, if closed areas are too small and/or spillover is extremely high, spillover negatively impacts population persistence and, eventually, fisheries yields (e.g., Polacheck 1990; DeMartini 1993; Moffitt et al. 2009). However, evolutionary modelling studies indicated that the propensity of fish to move outside MPAs and, therefore, fisheries benefits due to spillover, could decrease in the long-term, given that relatively sedentary individuals will have better survival following the creation of closed areas (Miethe et al. 2009).

The impacts of fish movement on MPA effects depend on fishing effort levels and fishing mortality distribution in nonprotected areas (Botsford et al. 2009; Grüss et al. 2011a). It has also long been established that closed areas are likely to have positive fisheries effects only when populations targeted by spatial protection efforts were already overexploited in nearby fished areas. Only under this condition can spillover and recruitment subsidy due to increased fish biomass in MPAs be sufficiently large to offset lost fishing opportunities due to closing areas in the long term (e.g., Holland and Brazee 1996; 


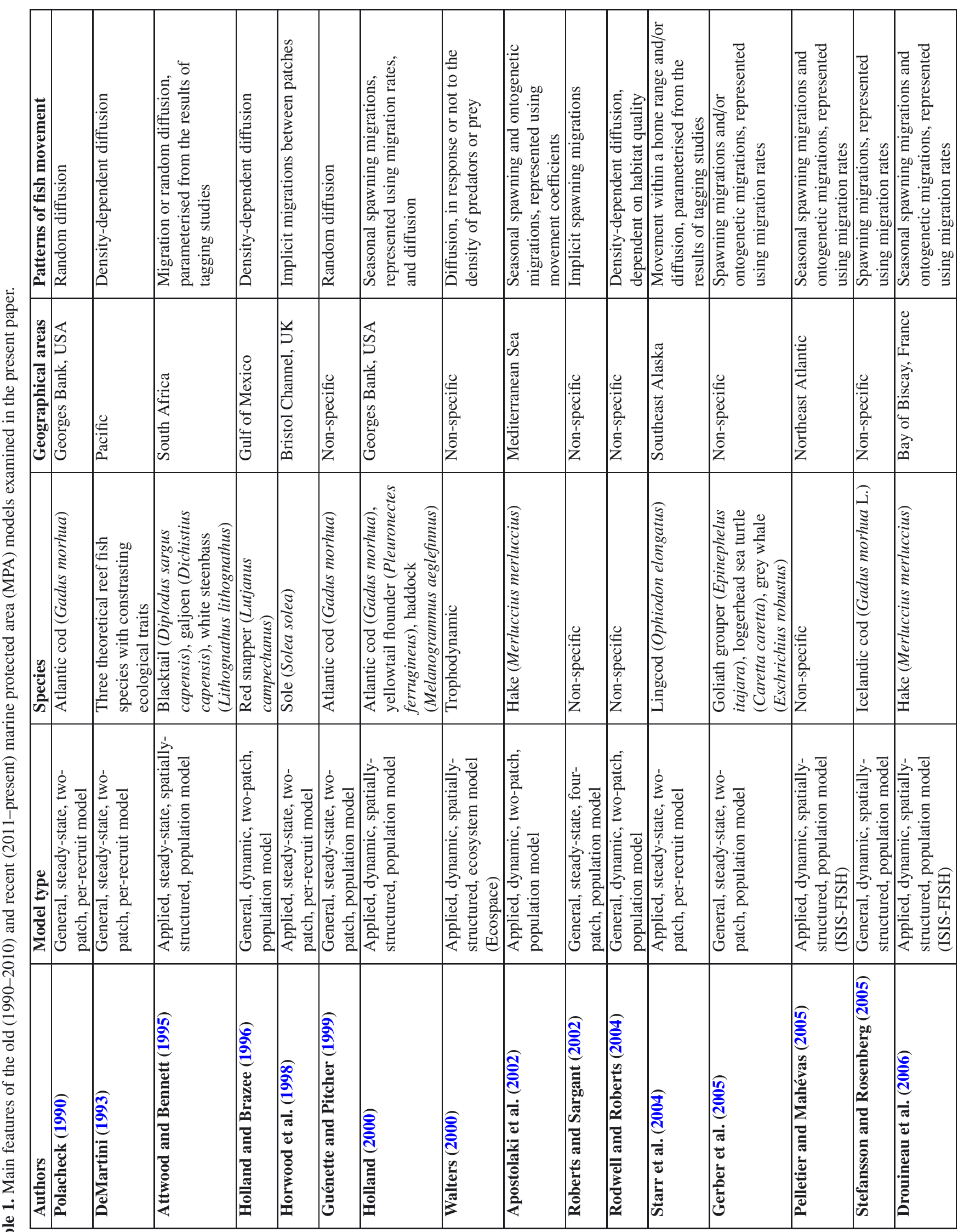




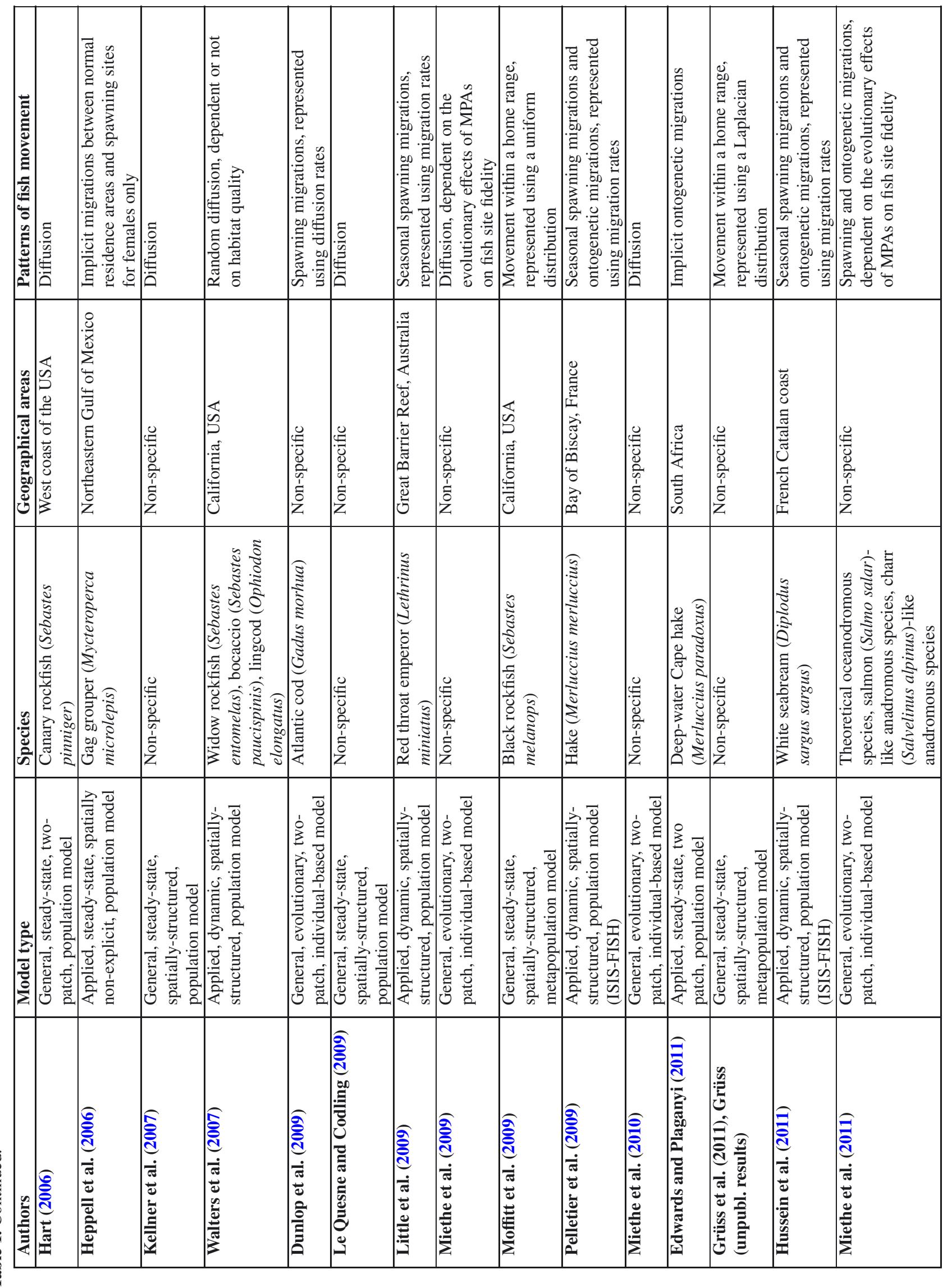


A. Grüss: Aquat. Living Resour. 27, 107-133 (2014)

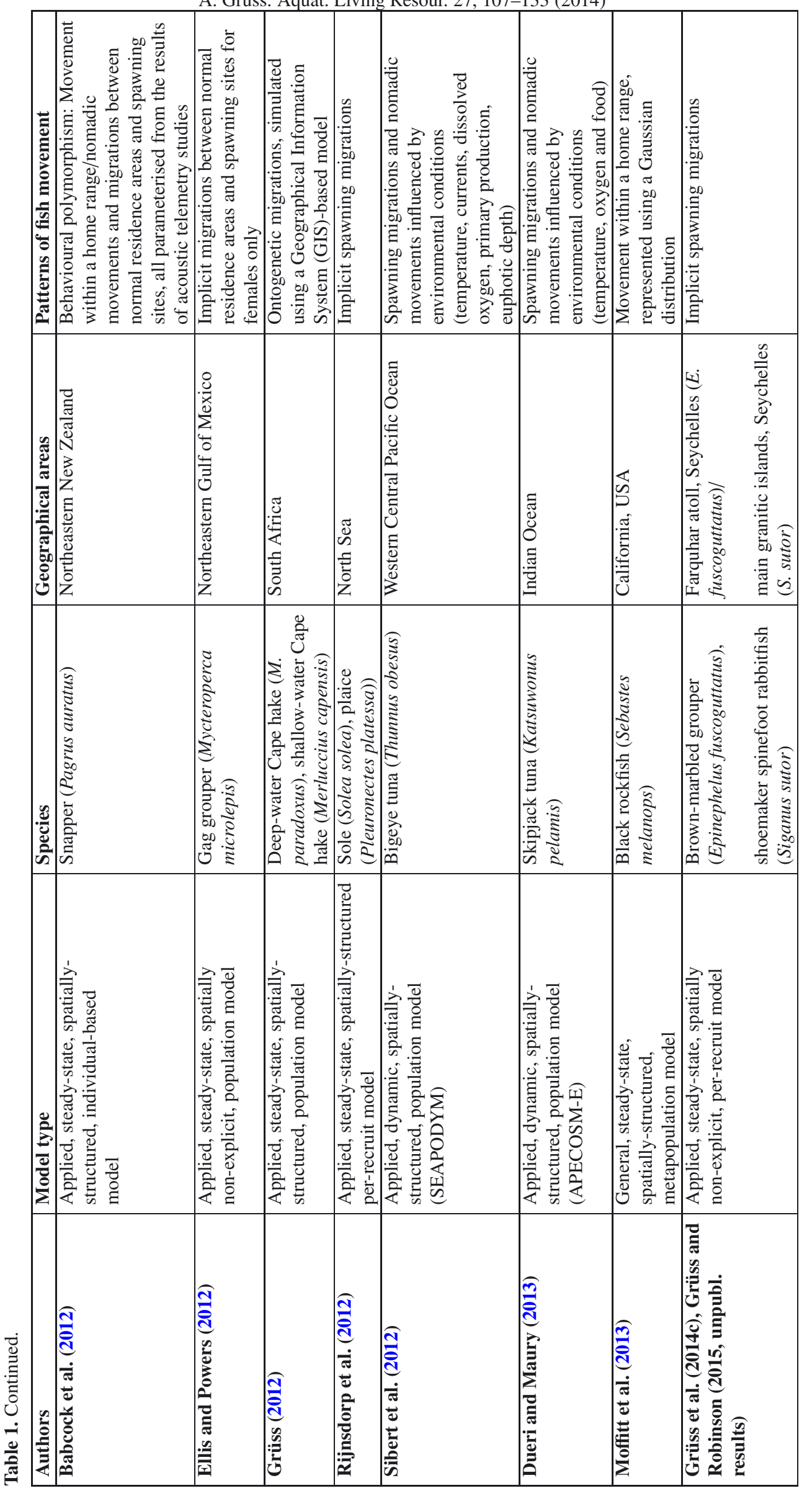


Guénette and Pitcher 1999; Hart 2006; Little et al. 2009). Moreover, high concentration of fishers on MPA boundaries to take advantage of spillover ("fishing-the-line") and the redistribution of the fishing effort formerly in closed areas to remaining fished areas ("fishing effort displacement") have the potential to significantly decrease the size of protected populations and, ultimately, levels of spillover and recruitment subsidy (e.g., Holland 2000; Walters 2000; Kellner et al. 2007; Walters et al. 2007).

Until recently, only three modelling studies examined the relative impacts of fish movement versus larval dispersal on fish conservation and fisheries yields with MPAs (Gerber et al. 2005; Le Quesne and Codling 2009; Moffitt et al. 2009). Gerber et al. (2005) employed a two-patch, age-structured population model to evaluate how adult migrations, ontogenetic migrations and larval dispersal interact with life-history traits to determine the long-term effects of MPAs on population growth rate. The authors found that the ability of MPAs to improve population growth rate was more reduced by migrations than by larval dispersal. Moffitt et al. (2009) used a spatially-structured metapopulation model to examine persistence and fisheries yields for a fish population with dispersing larvae and post-larval stages moving within a home range, where fishing effort displacement and the tendency of fishers to fish-the-line are not considered. They demonstrated that homerange movement has a strong negative impact on equilibrium population persistence in MPA networks relative to larval dispersal, even for movement spatial scales considerably smaller than MPA size. Moffitt et al. (2009)'s results also suggest that spillover has lesser potential to increase fisheries yields in the long-term than recruitment subsidy. Le Quesne and Codling (2009) found the opposite using a spatially-structured, agestructured population model representing fish movement as a diffusive process and accounting for fishing effort displacement and the tendency of fishers to fish-the-line, but where only the special cases of a uniform spatial distribution of larvae and non-dispersing larvae were considered.

While Gerber et al. (2005), Moffitt et al. (2009) and Le Quesne and Codling (2009) provide some insights into the impacts of fish movement on MPA effects relative to those of larval dispersal, the underlying mechanisms driving differences in the impacts of larval dispersal and fish movement as well as the generality of these impacts have not been clearly identified until recently. Furthermore, the implications of fish movement and larval dispersal ("ecological connectivity") for MPA effects relative to those of fishing-the-line and fishing effort displacement ("fishers movement") have never been rigorously examined.

Modelling studies conducted until recently usually focused on the long-term, equilibrium impacts of MPAs for mobile fish populations. Thus, the effects of MPAs reported in the rest of the present paper refer to long-term effects, unless otherwise specified. The rationale behind the focus of biological MPA models on the long-term, equilibrium impacts of MPAs is that most of the mobile fish species that are targeted by spatial protection efforts have a slow life history and may receive significant benefits from MPAs only after decades of effective protection (Palumbi 2004; Grüss et al. 2011a, 2014a). However, the creation of closed areas usually reduces fisheries yields in the short term by diminishing the total area available for harvest (e.g., Holland 2000; Rodwell and Roberts 2004; Dunlop et al. 2009). Therefore, it is of interest to know the extent of decreases in fisheries yields made from mobile fish populations in the short term, and the time needed for the biomass of these fish populations to consistently build up with MPAs and for yields to eventually increase via spillover and recruitment subsidy.

\subsection{How could MPAs benefit migratory fish populations and their fisheries without being extremely large?}

General modelling studies suggest that, to effectively protect adults and juveniles of migratory fish populations, closed areas need to be very large or networked to cover a large fraction of the total habitat area (e.g., Polacheck 1990; Stefansson and Rosenberg 2005; Le Quesne and Codling 2009). Because the establishment of large MPAs or MPA networks covering a large area is costly, there is increasing interest in strategies for protecting smaller areas where fish spend an inordinate fraction of time and/or are highly vulnerable to fishing (e.g., areas associated with specific developmental stages, such as nursery or spawning areas). These more limited MPAs are referred to as "targeted MPAs" because they aim to protect specific fractions of fish populations rather than their entire life cycle (Kaplan et al. 2010; Grüss et al. 2011a).

The conservation and fisheries effects of targeted MPAs have been evaluated in several modelling studies (e.g., Pelletier and Magal 1996; Apostolaki et al. 2002; Roberts and Sargant 2002; Heppell et al. 2006; Dunlop et al. 2009). Most of these studies used patch models, where each patch represents a specific developmental stage (spawning and nursery areas) or seasonal habitat (spawning and feeding (normal residence) areas), with explicit or implicit migrations of fishes between patches (Table 1). One can distinguish between two cases: (1) targeted MPAs for temperate migratory fish populations; and (2) targeted MPAs for tropical reef fish populations forming transient spawning aggregations (hereafter often simply referred to as "aggregation-forming populations" or "aggregative populations"). Within nursery, reproductive and feeding areas, individuals of a migratory fish population move within a home range or undertake nomadic movements (Fig. 1). However, the spatial extent of these movements is generally much smaller than the spatial extent of targeted MPAs (e.g., Semmens et al. 2006; Bradbury et al. 2008; Hutchinson and Rhodes 2010; Armstrong et al. 2012) and, therefore, these movements are ignored in modelling studies studying the impacts of nursery, spawning and normal residence MPAs.

\subsubsection{Targeted MPAs in temperate regions}

In temperate latitudes, the nursery, feeding and spawning areas of migratory fish populations are generally all relatively extensive. In this context, it is necessary to determine which of these areas should be preferentially protected. Apostolaki et al. (2002) devised a two-patch, size-structured population model to evaluate the effects of spawning and nursery MPAs for Mediterranean hakes (Merluccius merluccius) under a range of 
fishing mortalities. The authors found that spawning area closures may enhance fisheries yields only when hakes are overexploited and the fishing effort previously in MPAs is not redistributed to hake nursery areas. Using two-patch, age-structured models, Pelletier and Magal (1996) and Horwood et al. (1998) showed that spawning MPAs may do more harm than good for migratory fish populations since high fishing effort may then be redirected into nursery areas. Results of Pelletier and Magal (1996) suggest that better SSB and yield levels would have been obtained for the saithe (Pollachius virens) population of western Scotland in the 1980s if the population had been fished after the spawning season and nursery area closures had been implemented. Dunlop et al. (2009) developed a general two-patch, age-structured individual-based model to predict the effects of closed areas on fisheries-induced evolution under migration. The authors found that MPAs in feeding areas, which protect both adults and juveniles, reduced fisheries-induced evolution, but not MPAs in spawning areas, which protect only adults.

Relatively important modelling efforts have been undertaken until recently to evaluate targeted MPA effects for temperate migratory fish populations and their fisheries, and existing patch models concur on the fact that juveniles of these populations should be the preferential targets of spatial protection efforts. Nevertheless, complex spatially- and, eventually, seasonally-explicit models representing migrations between feeding and spawning areas and/or ontogenetic migrations and fishing fleet dynamics are also needed to provide detailed assessments for specific migratory populations and gain insights regarding the interaction between different fish movement types, fleet dynamics and the spatial distribution of MPAs. ISIS-Fish (Integration of Spatial Information for Simulation of Fisheries) is one such model (Pelletier and Mahévas 2005; Pelletier et al. 2009). ISIS-Fish is a spatiallystructured, length-structured model, which relies on three interacting submodels pertaining, respectively, to fish population, exploitation, and management of multi-species multifleet (mixed) fisheries. It takes into account fishers' behaviour in response to management measures. Drouineau et al. (2006) used ISIS-FISH to investigate the consequences of an MPA aimed at protecting hake (M. merluccius) spawners for the French Norway lobster (Nephrops norvegicus)-hake mixed fishery of the Bay of Biscay. The authors found that an MPA in the hake spawning zone had limited conservation and fisheries effects. Pelletier et al. (2009) explored the impacts of an MPA aimed at protecting hake juveniles for the same fishery with ISIS-FISH. They showed that, under the most conservative assumption about Norway lobster larval dispersal, an MPA in the hake nursery zone improved the status of the Norway lobster stock but not the overall economic return for the Norway lobster-hake fishery. In comparison, another management measure (restrictions on fishing gears) enhanced both Norway lobster stock status and the economic return for the fishery (Pelletier et al. 2009).

\subsubsection{Targeted MPAs for aggregation-forming populations}

Many socio-economically important tropical reef fish populations undertake migrations to form transient spawning aggregations at sites located a few to hundreds of kilometers from their normal residence areas (Domeier and Colin 1997). For these populations, spawning individuals are usually the targets of spatial protection efforts since fishing mortality is considerably high at spawning sites and spawning aggregation areas are of small size compared to normal residence areas (Rhodes and Warren-Rhodes 2005; Sadovy and Domeier 2005). In the case of aggregation-forming reef fish populations, it is of interest to assess whether spawning area closures may significantly improve fish reproductive capacity, but also whether they may normalise female:male sex ratio when the study population is protogynous (i.e., matures first as a female and then changes to male), since for protogynous populations a decrease of the relative number of males is thought to considerably reduce egg fertilisation rates (e.g., Coleman et al. 1996; Koenig et al. 1996).

Until recently, only one model explored the potential impacts of targeted MPAs for aggregation-forming populations (Heppell et al. 2006). Heppell et al. (2006) developed a spatially non-explicit, age-structured population model to evaluate the conservation effects of MPAs for the gag grouper ( $M y c$ teroperca microlepis) population of the northeastern Gulf of Mexico, alone or in combination with other management measures (e.g., fishing effort reduction). Importantly, the authors found that spawning reserves helped normalising female:male sex ratio but were less effective at improving fish reproductive capacity than marine reserves implemented in normal residence areas (protecting juveniles and mature females outside the spawning season) or fishing effort reduction, especially in presence of fishing effort displacement. Heppell et al. (2006) focused on the conservation effects of targeted marine reserves for a data-rich aggregation-forming fish population. Therefore, until recently, many issues remained to be addressed to fully assess the potential impacts of spawning aggregation reserves versus normal residence reserves, including: (1) the fisheries effects of these area closures; and (2) the impacts of these area closures in data-limited contexts, which applies to the majority of tropical reef fish populations forming transient spawning aggregations (Johannes 1998; Sadovy and Domeier 2005; Sadovy de Mitcheson et al. 2008).

\subsection{Can MPAs benefit highly migratory fish populations and the fisheries targeting them?}

Regarding highly migratory fish populations, one can distinguish between: (1) highly migratory populations that do not follow clear migration patterns and exhibit large nomadic movements within habitat preferences (e.g., populations of skipjack tuna (Katsuwonus pelamis) and yellowfin tuna (Thunnus albacares); Stequert and Ramcharrum 1996; Schaefer and Fuller 2010; Schaefer et al. 2014); and (2) highly migratory populations that follow clear spawning and feeding migration patterns (e.g., population of bigeye tuna (Thunnus obesus) of the Western Central Pacific Ocean, and populations of Pacific bluefin tuna (Thunnus orientalis); Block et al. 2011; Kaplan et al. 2014; Madigan et al. 2014). In the case of highly migratory populations following clear spawning and feeding migration patterns, fish individuals undertake nomadic movements within spawning and feeding areas (Fig. 1). In any 
case, the spatial scale of nomadic movements of highly migratory populations is likely to be larger than the spatial scale of an MPA (Sibert and Hampton 2003; Hobday et al. 2011; Kaplan et al. 2014). Until recently, no modelling study has investigated the conservation and fisheries effects of MPAs for highly migratory fish populations.

\subsection{To which extent does variability of fish movement affect MPA effects?}

One can distinguish between two types of variability of movement in a particular life stage of a fish population: (1) variability in site fidelity; and (2) "behavioural polymorphism".

Adult individuals within a migratory fish population are in general faithful to specific spawning and feeding areas (e.g., Domeier and Colin 1997; Sadovy and Eklund 1999; Rooker et al. 2008; Cury and Pauly 2013). For example, adults of Atlantic bluefin tuna (Thunnus thynnus) intermingle in feeding grounds off the east coast of North America and split into two distinct subpopulations during the reproductive season, one migrating to specific spawning grounds of the Mediterranean Sea, the other to specific spawning grounds of the Gulf of Mexico (Rooker et al. 2008). However, a few studies have revealed that in some migratory fish populations a proportion of adult individuals is not faithful to specific spawning sites (e.g., shoemaker spinefoot rabbitfish, Siganus sutor; Bijoux et al. 2013; goliath grouper, Epinephelus itajara; C. Koenig, Florida State University Coastal \& Marine Laboratory, St. Teresa, Florida, pers. comm.). The lack of site fidelity of a large fraction of adults ("straying") may significantly decrease the conservation benefits of targeted MPAs by exposing a fraction of the population targeted for protection to fishing, similarly to fish movement within a home range. Until recently, no modelling study has considered the impacts of straying on targeted MPA effects.

"Behavioural polymorphism" refers to the situation where different patterns of fish movement are manifested in the same population within the same life stages (Attwood and Bennett 1995). For instance, in some fish populations, some adult individuals move within a home range, whereas others undertake nomadic movements (e.g., Parsons et al. 2003; Egli and Babcock 2004; Starr et al. 2004). Moreover, in some migratory populations, a fraction of the adult population migrates to specific spawning sites every year, while the rest of the adult population occupies the same areas all year round (e.g., Willis et al. 2003; Bradbury et al. 2008; Parsons et al. 2011). To determine how behavioural polymorphism affects the conservation and fisheries effects of closed areas, the representation of fish movement in models should ideally be derived from the results of movement studies (e.g., using both acoustic and satellite telemetry; Grüss et al. 2011a). Such a representation of fish movement has been carried out in a limited number of modelling studies (Attwood and Bennett 1995; Starr et al. 2004). However, the impacts of variations in the proportion of fish exhibiting specific movement patterns on MPA effects have not been evaluated until recently.

\section{What we recently learnt}

Until 2011, the four fundamental questions related to the impacts of MPAs for mobile fish populations and their fisheries identified in the Introduction have been only partially addressed, or not addressed at all. Hereinafter, I review and discuss how these fundamental questions have been explored in more details in published and unpublished modelling studies during the last three to four years (Tables 1 and 2).

\subsection{How does adult and juvenile movement affect MPA effects?}

\subsubsection{Impacts of fish movement within a home range versus larval dispersal}

Grüss et al. (2011b) developed a spatially-structured metapopulation model providing a general, rigorous conceptualisation of the impacts of fish movement within a home range on the conservation and fisheries effects of marine reserve networks relative to those of diffusive larval dispersal. A single functional form (Laplacian distribution (exponential decay)) was used for both fish movement and larval dispersal, providing a comparative platform for assessing which form of ecological connectivity has greater impact on the persistence and yields of an overexploited fish population, for different configurations of marine reserve networks at model equilibrium, in presence or absence of fishing effort displacement and/or fishing-the-line (Fig. 2a). The system modeled in Grüss et al. (2011b) is a system of periodically-spaced, uniformly-sized marine reserves. Concretely, a single marine reserve is established in Grüss et al. (2011b)'s model and circular boundaries are implemented.

Grüss et al. (2011b)'s results confirmed that adult and juvenile movement has a considerable impact on the conservation and fisheries effects of MPAs, and demonstrated that the persistence of a population with mobile post-larval stages requires significantly more habitat area in MPAs and/or larger MPAs than for an equivalent population with larvae dispersing over the same spatial scale. Differences in persistence for fish movement versus larval dispersal were found to be accentuated in presence of fishing-the-line and fishing effort displacement.

Grüss et al. (2011b) identified the underlying mechanisms driving differences in the impacts of larval dispersal and fish movement on MPA effects. The authors demonstrated that larval dispersal and fish movement are fundamentally different in how they expose "reserve individuals" to fishing pressure. Larval dispersal exposes youngs produced by individuals residing in MPAs but transported out of protected areas to fishing pressure, whereas those larvae that do manage to settle in MPAs are protected over their entire life span. Fish movement, on the other hand, exposes reserve individuals to fishing during the period they spend in fished areas, and, therefore, given sufficient movement, all reserve individuals will be accessible to fisheries at some point (Fig. 2b). This accessibility explains both the need for larger MPAs and the fact that fishing effort displacement is much more effective at reducing MPA protection when fish are mobile. The conceptual 


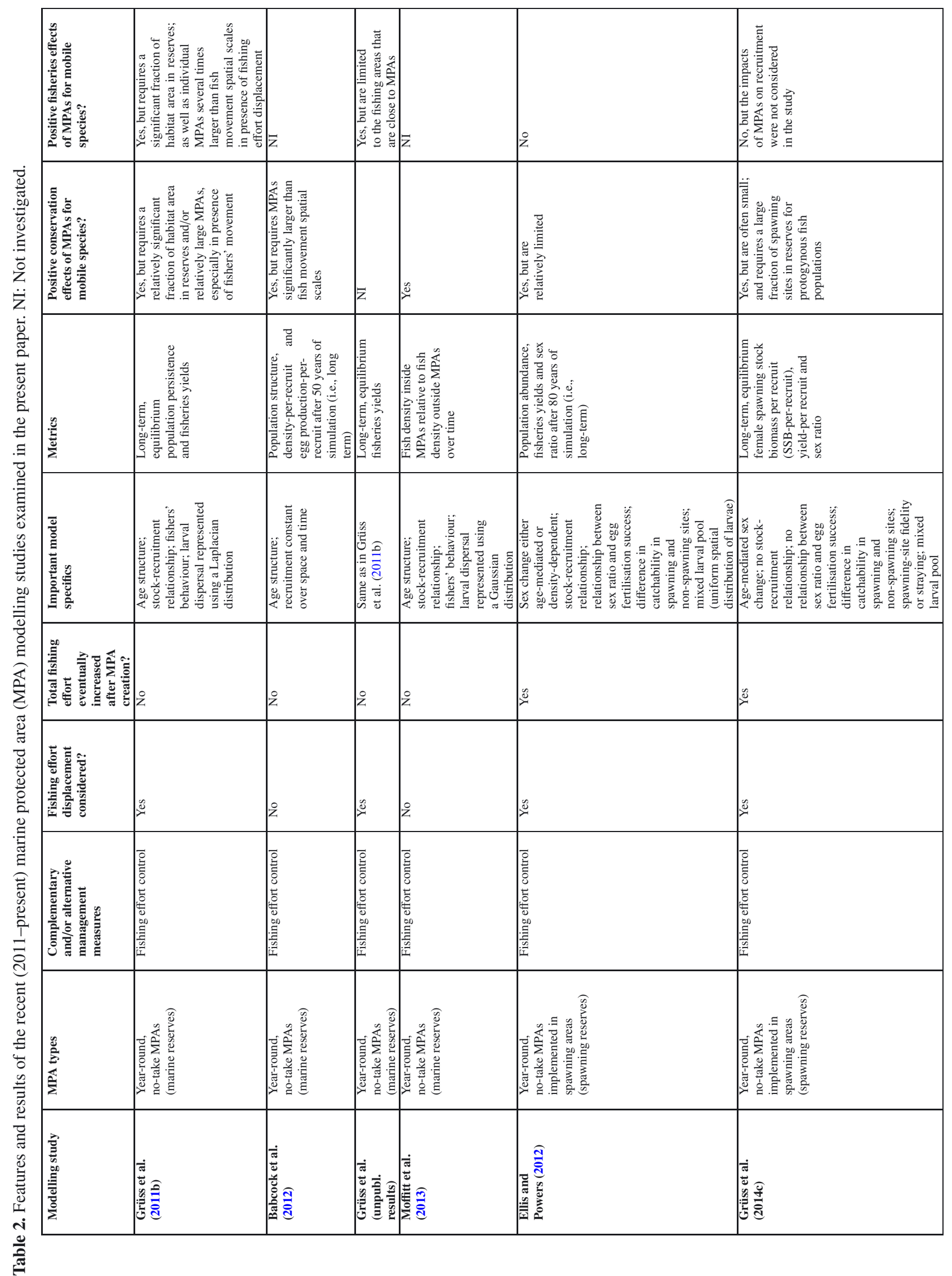




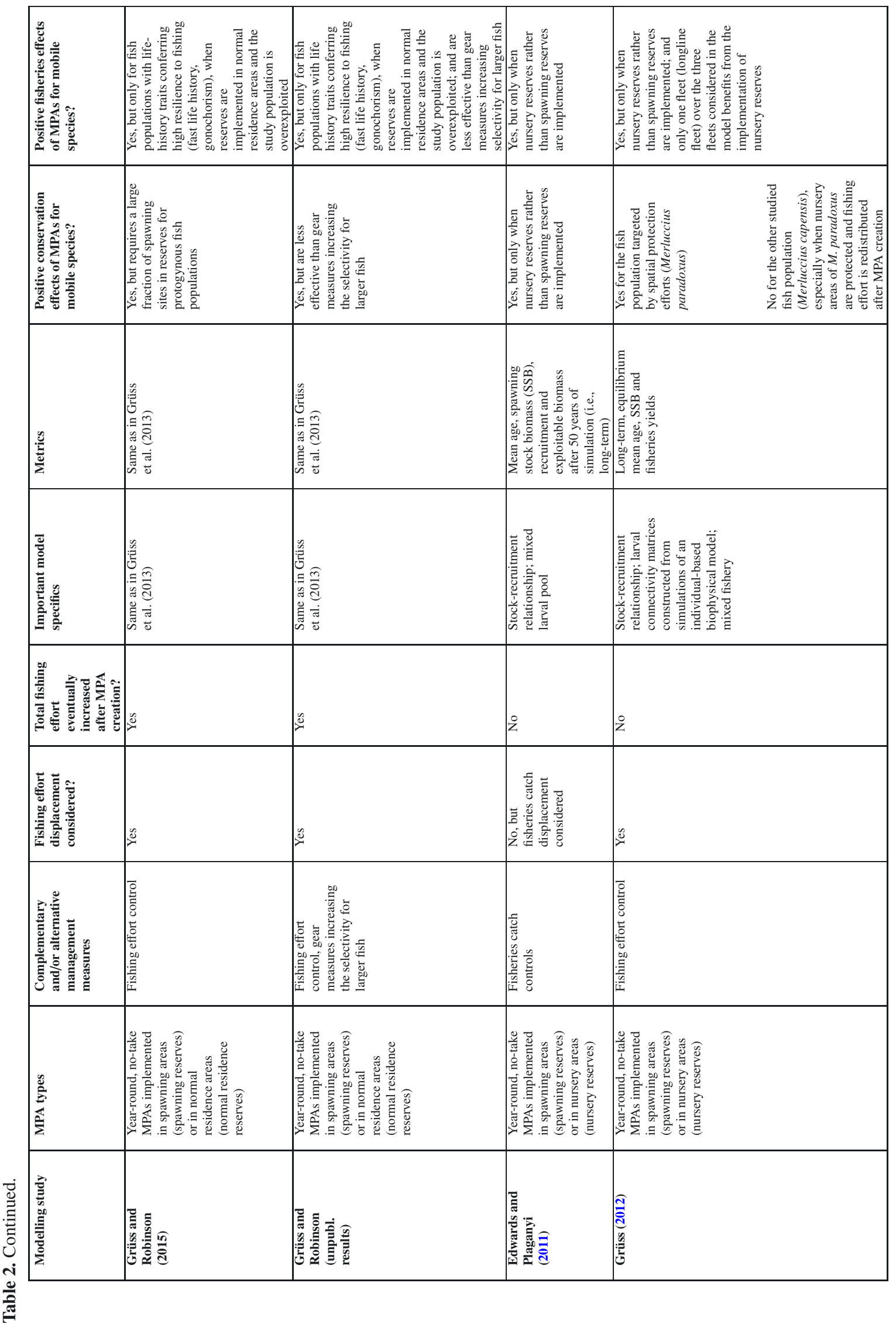




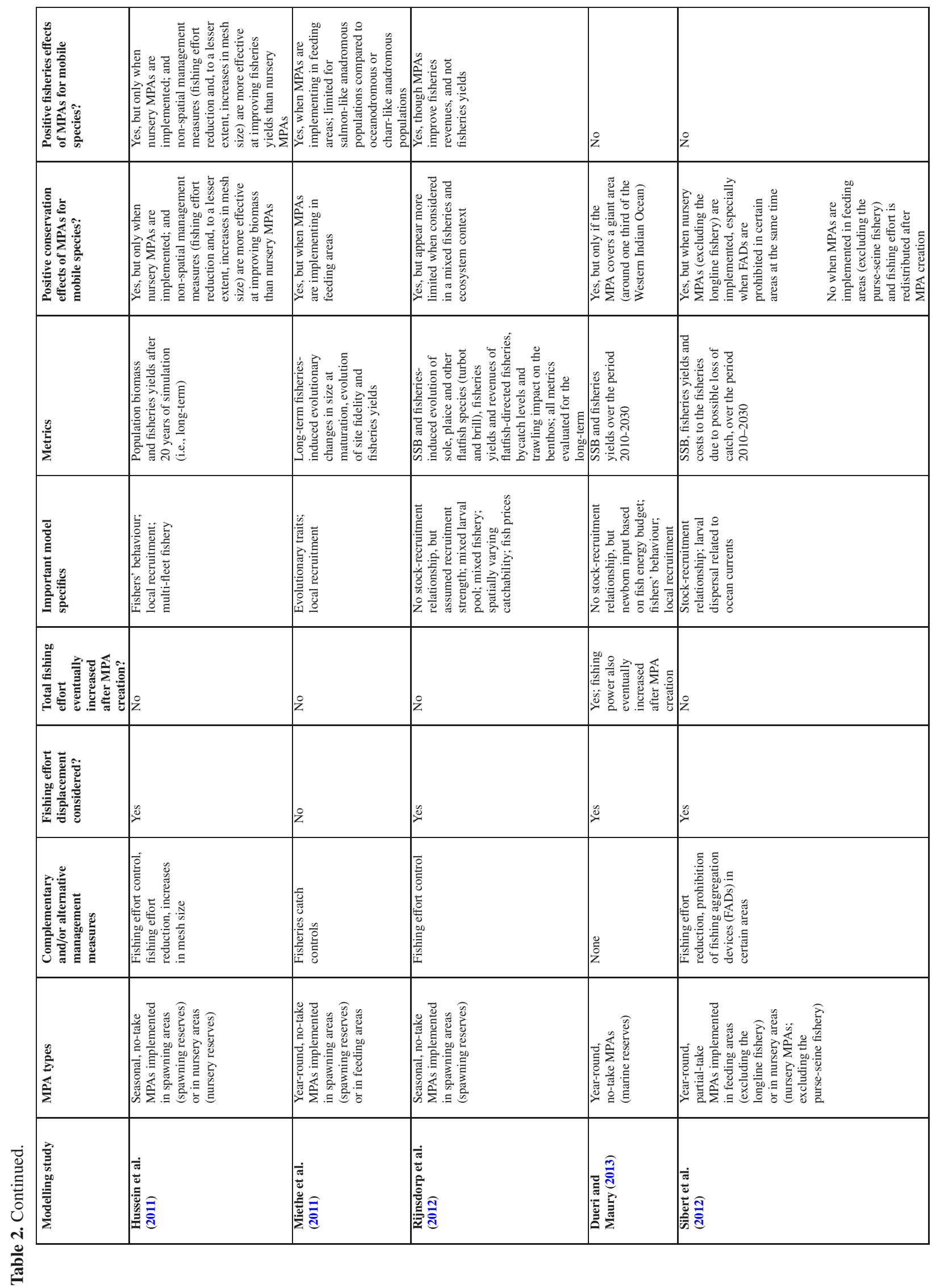




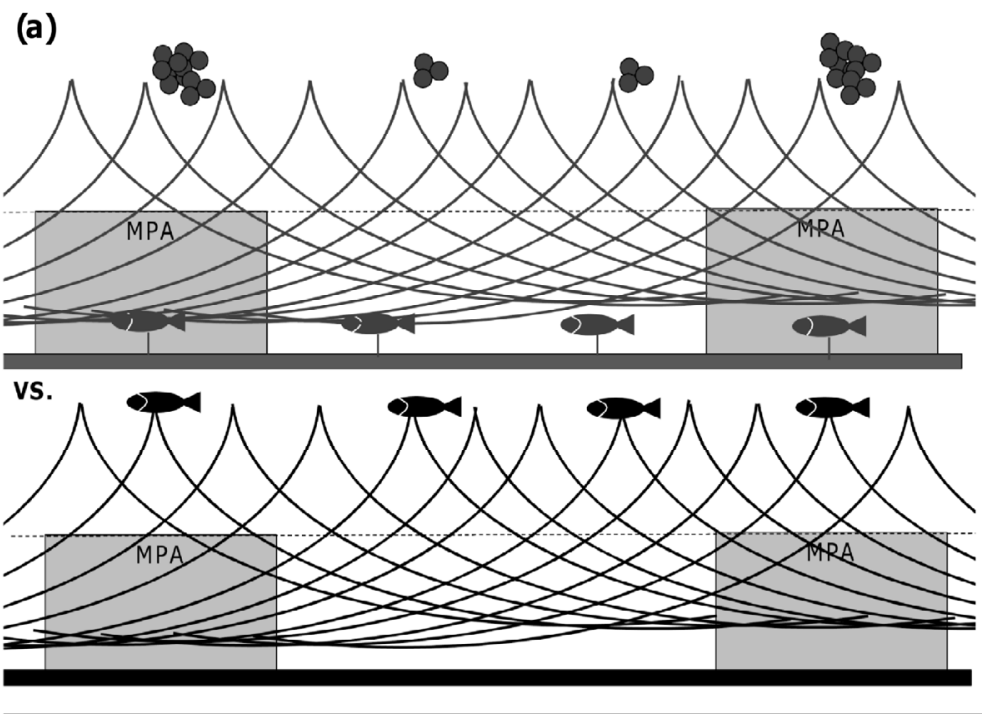

(b)

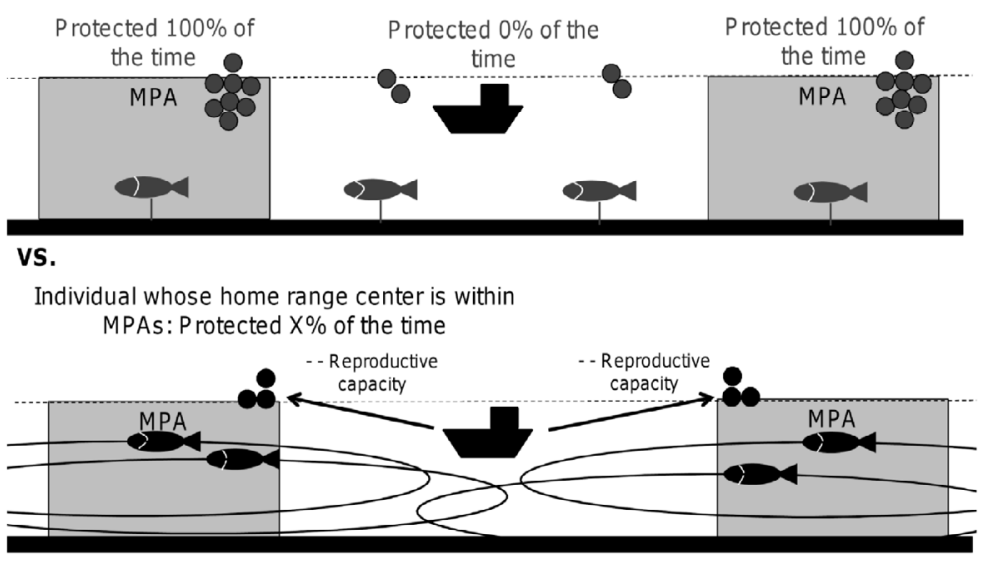

Fig. 2. (a) Grüss et al. (2011b) examined the impacts of fish movement within a home range on the effects of marine protected area (MPA) networks relative to those of diffusive larval dispersal in a system of periodically-spaced, uniformly-sized marine reserves, where fish movement and larval dispersal were both modelled using a Laplacian distribution (exponential decay). (b) Grüss et al. (2011b) demonstrated that larval dispersal and fish movement are fundamentally different in how they expose "reserve individuals" to fishing. When ecological connectivity is restricted to larval dispersal, reserve individuals are protected over their entire life span (upper panel). Fish movement exposes reserve individuals to fishing during the period they spend in fished areas, and, given sufficient movement, all reserve individuals will be accessible to fisheries at some point. Therefore, fish movement offers an opportunity to fishing to significantly reduce the reproductive capacity of the "reserve population" (lower panel).

model developed in Grüss et al. (2011b) indicates that individual MPAs should be several times larger than fish movement spatial scales to ensure population persistence in this situation.

Babcock et al. (2012) designed a spatially-structured, individual-based model to investigate the long-term impacts of marine reserves on population structure, density-per-recruit and egg production-per-recruit for a population of snapper (Pagrus auratus) in northeastern New Zealand, which is analysed in more details below (Sect. 3.4.1; Table 2). Larval dispersal is not represented in Babcock et al. (2012)'s model, while fish movement is parameterized from the results of acoustic telemetry studies (see details in Sect. 3.4.1). Consistent with Grüss et al. (2011b), Babcock et al. (2012) demonstrated that fish movement has a considerable negative impact on MPA conservation effects. According to Babcock et al. (2012), marine reserves should be many times larger than the move- ment spatial scales of snapper in their normal residence areas to ensure that the snapper reserve population resembles more to an unfished population than to fished population, so as to improve egg-production capacity at a regional level.

With regards to MPA fisheries effects, Grüss et al. (2011b) showed that which of fish movement and larval dispersal is more beneficial to fisheries yields depends essentially on the fraction of habitat area covered by MPAs and the fate of the fishing effort previously in protected areas. Recruitment subsidy has greater potential to improve fisheries yields than spillover when a small fraction of habitat area is protected. On the other hand, in absence of fishing effort displacement, high fisheries yields are produced for a larger set of MPA configurations for fish movement than larval dispersal when a significant fraction of habitat area is set aside in MPAs. Fishing effort displacement considerably alters the fisheries benefits of MPAs 
Fish movement

(a)

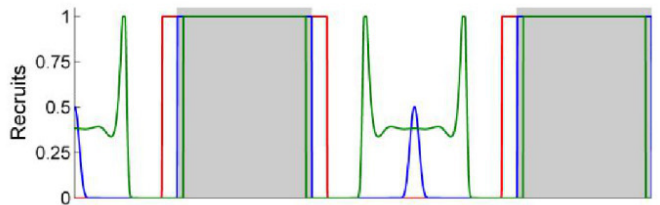

(c)

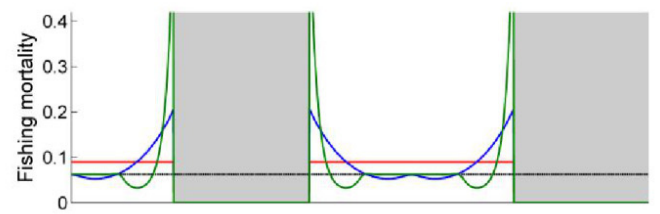

(e)

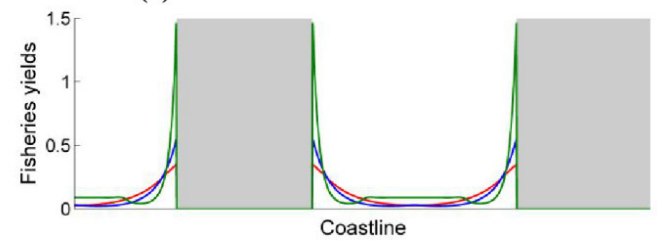

Fish movement + larval dispersal

(b)

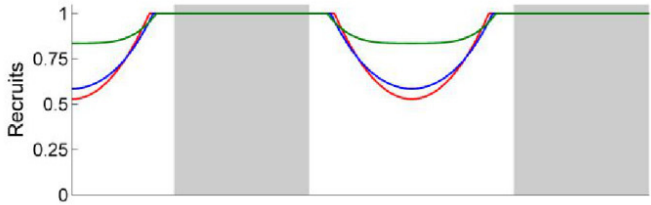

(d)

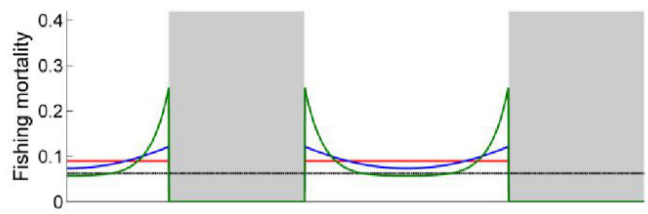

(f)

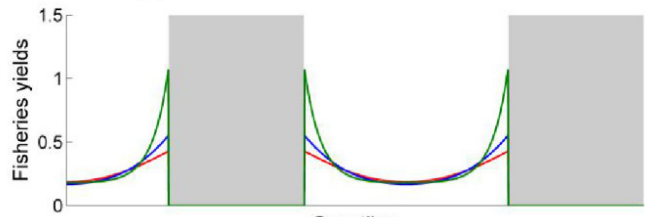

- $\gamma_{1}-\gamma_{2}=2 \gamma_{1}-$ no fishers' behaviour

Fig. 3. Spatial patterns of (a, b) recruitment, $(c, d)$ fishing mortality rate, and (e, f) fisheries yields for a system of periodically-spaced, uniformlysized marine reserves (grey areas) at equilibrium, in Grüss (unpubl. results). (a, c, e) are for populations with post-larval stages moving within a home range and non-dispersing larvae, whereas $(b, d, f)$ are for populations with post-larval stages moving within a home range and larvae dispersing over the same spatial scale as the post-larvae. Fishing effort is uniform outside reserves for red curves. For the green and blue curves, fishing effort distribution in the non-protected areas depends on local expected fisheries yields, with the value of $\gamma$ being 1.2 for green curves and 2.4 for blue curves. $\gamma$ is a measure of the difference among fishers in perception of benefits of operating at a location. The units of recruitment are arbitrary, but consistent between simulations. The dashed black line on (c) and (d) represents the fishing mortality rate above which the population collapses in the absence of reserves. (For interpretation of the references to colour in this figure legend, the reader is referred to the online version of the article.)

for mobile fish populations. Maximum fisheries yields are low in this situation, and occur when almost all the habitat area is set aside in MPAs and for MPA widths several times larger than fish movement spatial scales. This is due to the fact that population persistence is achieved in this situation by establishing large closed areas to ensure that some individuals have very little exposure to extremely high fishing pressure outside protected areas. This has the effect of rendering many individuals inaccessible to fishing and, therefore, limiting fisheries yields. In contrast, fishing effort displacement has only a marginal effect on fisheries yields for fish populations with sedentary post-larval stages and dispersing larvae, so that recruitment subsidy has usually greater potential to improve fisheries yields than spillover in presence of fishing effort displacement (Grüss et al. 2011b).

\subsubsection{Impacts of fish movement within a home range combined with larval dispersal}

In addition to evaluating the impacts of fish movement versus larval dispersal on MPA effects, Grüss et al. (2011b) analysed how fish movement within a home range combined with larval dispersal affects the conservation effects of MPAs. The results of this supplementary analysis indicate that population persistence often occurs for fewer MPA configurations when fish movement and larval dispersal are combined rather than for exclusively one or the other form of ecological connectivity. This likely stems from the fact that larval dispersal reduces self-recruitment needed for population persistence inside MPAs at the same time that fish movement reduces the reproductive capacity of individuals recruiting in MPAs.

Grüss (unpubl. results) used Grüss et al. (2011b)'s model to examine how fish movement within a home range combined with larval dispersal affects the spatial distribution of fishers in non-protected areas. This additional work suggests that spillover may only improve the yields of fishers operating in proximity to protected area borders. When larval dispersal superposes to vessels fishing close to protected area borders, MPAs have the potential to also improve the yields of fishers operating in more distant areas (Fig. 3). This result concurs with discussions made in review papers (Halpern and Warner 2003; Roberts et al. 2005) and findings of an empirical 
study recently published in the journal Nature Communications (Kerwath et al. 2013).

\subsubsection{Impacts of fish movement over time}

Moffitt et al. (2013) developed a general, spatiallystructured metapopulation model similar to that of Grüss et al. (2011b), except that: (1) this model is dynamic; (2) it focuses on the impacts of an individual no-take MPA on fish density; and (3) a Gaussian distribution rather than a Laplacian distribution was used to represent both home-range movement and larval dispersal (Table 2). The main goal of Moffitt et al. (2013)'s study was to explore the spatio-temporal responses of fish density to a range of MPA sizes, fishing intensities, larval dispersal distances and home-range sizes over a 50-year period, so as to help the interpretation of MPA monitoring studies. Part of this study therefore informs us about the consequences of fish movement for MPA effects on relative population density (i.e., fish density inside closed areas relative to fish density outside closed areas) over time.

Moffitt et al. (2013) demonstrated that the largest effects of closed areas on population density should be expected in fished sites located at least at a distance equal to two home ranges from the MPA edges, and after two generations (fish lifespans) have passed since MPA establishment. The authors also found that MPA monitoring studies over time (after versus before) should provide a better assessment of the conservation effects of closed areas for mobile fish populations than monitoring over space (inside versus outside). These results confirm that it takes a long time for the abundance of mobile fish populations to build up with MPAs, and that all applied MPA modelling studies should ideally analyse the transient responses of mobile species to provide realistic expectations to stakeholders.

\subsection{How could MPAs benefit migratory fish populations and their fisheries without being extremely large?}

\subsubsection{Targeted MPAs for aggregation-forming populations}

Ellis and Powers (2012) designed a spatially non-explicit, age-structured population model on the basis of Heppell et al. (2006)'s model to examine the long-term impacts of yearround spawning reserves of different sizes on the abundance, female: male sex ratio (hereafter usually simply referred to as "sex ratio") and fisheries yields of the data-rich gag grouper population of the northeastern Gulf of Mexico. Grüss et al. (2014c) constructed a spatially non-explicit, age-structured, per-recruit model to assess the long-term, equilibrium impacts of closing a fraction or all spawning sites on the female SSB-per-recruit, sex ratio and yield-per-recruit of aggregationforming populations in data-limited situations. Grüss et al. (2014c)'s model avoids the need for specifying a relationship linking egg fertilisation rate to sex ratio and a stockrecruitment relationship, both of which are usually unknown or uncertain for aggregative populations (Johannes 1998; Alonzo and Mangel 2004; Sadovy and Domeier 2005). The model was applied to two fish populations from Seychelles with contrasting life-history features: the Siganus sutor population of the main granitic islands, which has a fast life history and is gonochoristic; and the brown-marbled grouper (Epinephelus fuscoguttatus) population of Farquhar Atoll, which has a slow life history and is protogynous. Grüss et al. (2014c) considered that fishes are either entirely faithful or entirely unfaithful to spawning sites. Both in Ellis and Powers (2012) and Grüss et al. (2014c), fish implicitly migrate between normal residence areas and spawning areas.

Ellis and Powers (2012) and Grüss et al. (2014c) showed that, for a wide range of fishing effort levels, spawning reserves are in general effective at enhancing the abundance and SSB-per-recruit of aggregation-forming populations and at normalising their sex ratio, but that these benefits are often small. However, Grüss et al. (2014c) demonstrated that, in the likely situation where E. fuscoguttatus individuals are faithful to specific spawning sites and fishing effort is redistributed, the female:male sex ratio of its fished subpopulation may become dramatically high, thereby potentially reducing population-wide egg fertilisation in a significant manner unless a large fraction of spawning sites is protected.

Both Ellis and Powers (2012) and Grüss et al. (2014c) found that spawning reserves had overall no positive fisheries effect for aggregative populations. In Ellis and Powers (2012), in the absence of fishing effort displacement, fisheries yields increased only slightly with the fraction of spawning sites in reserves and then declined as the area protected grew large. When the fishing effort previously in reserves was redistributed, fisheries yields decreased sharply with the fraction of spawning sites in reserves (Ellis and Powers 2012). In Grüss et al. (2014c), increases in yield-per-recruit (exploitable biomass) with spawning area closures did not occur or were negligible, for both $S$. sutor and E. fuscogutattus, regardless of the fate of fishing effort previously in reserves and the degree of fish spawning-site fidelity. However, Grüss et al. (2014c) suggested that fisheries yields may improve when a large fraction of spawning sites is placed in reserves through recruitment subsidy, if (1) the study populations were recruitment limited before reserve establishment; and (2) increases in SSB-perrecruit compensate for lost opportunities caused by spawning area closures.

Grüss and Robinson (2015) modified Grüss et al. (2014c)'s model to compare the conservation and fisheries effects of spawning reserves to those of normal residence reserves for both the $S$. sutor population of the main granitic islands and the E. fuscoguttatus population of Farquhar Atoll. Grüss and Robinson (2015)'s model considers polymorphism in spawning behaviour to account for the fact that only a fraction of adults is faithful to spawning sites in some aggregationforming populations, as was recently shown for $S$. sutor in the main granitic islands (Bijoux et al. 2013).

Overall, Grüss and Robinson (2015)'s results suggested that protecting a fraction of normal residence areas is more effective in providing both conservation and fisheries benefits for $S$. sutor than protecting a fraction or all spawning sites. The application of Grüss and Robinson (2015)'s model to E. fuscoguttatus showed that normal residence reserves do not improve the yield-per-recruit of the species, and are overall 
(a) $\mathrm{C}_{\mathrm{r}}=0.3$

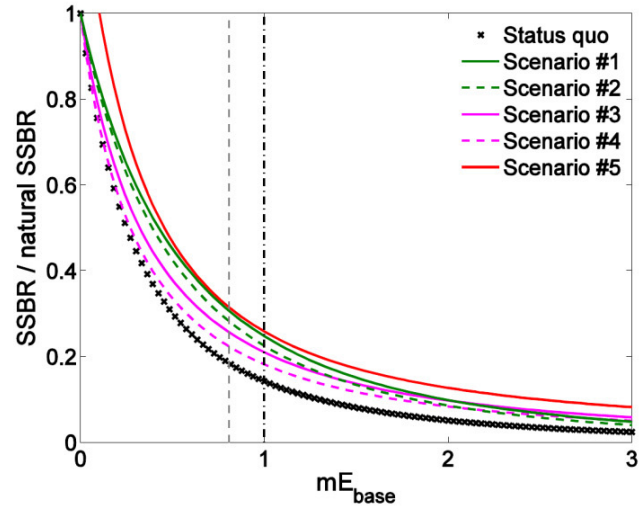

(c) $\mathrm{C}_{\mathrm{r}}=0.3$

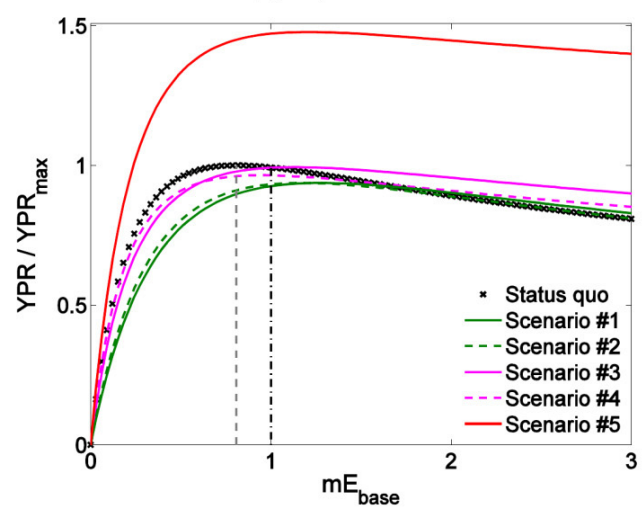

(b) $\mathrm{C}_{\mathrm{r}}=0.6$

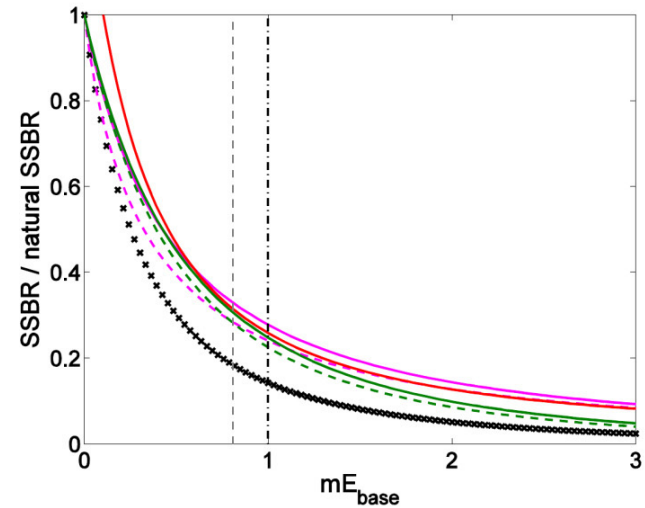

(d) $\mathrm{C}_{\mathrm{r}}=0.6$

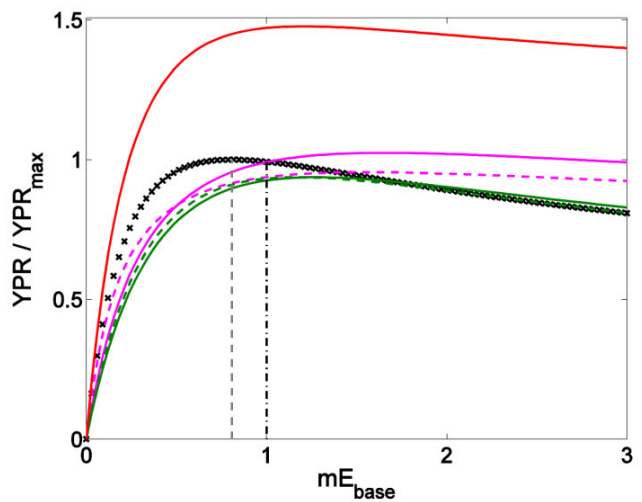

Fig. 4. (a, b) Spawning stock biomass-per-recruit (SSBR) over natural SSBR of Siganus sutor, and (c, d) yield-per-recruit of the species normalised by maximum yield-per-recruit of the species in the absence of reserves (YPR/YPR $\mathrm{max}_{\text {) }}$ ) as a function of multiplier of current fishing effort ( $\left.m E_{\text {base }}\right)$, for five management scenarios (Grüss and Robinson 2015). All spawning sites are set aside as reserves for Scenarios \#1-2. The fishing effort previously in reserves disappears in Scenario \#1, while it is fully redistributed to normal residence areas in Scenario \#2. For Scenarios \#3-4, the fraction of normal residence areas in reserves, $C_{r}$, is $30 \%$ and $60 \%$ for $(\mathrm{a}, \mathrm{c}$ ) and (b, d), respectively. The fishing effort previously in reserves disappears in Scenario \#3, while it is fully redistributed to non-protected normal residence areas in Scenario \#4. For Scenario \#5, gear measures increasing the size of recruitment of $S$. sutor into the trap fishery from $16.15 \mathrm{~cm}$ to $23 \mathrm{~cm}$ (size at sexual maturity) are implemented. For all panels, the vertical dashed-dotted black line indicates the annual fishing effort currently exerted on the population, $E_{\text {base }}$, whereas the vertical dashed grey line indicates the value of annual fishing effort at which yield-per-recruit reaches a maximum for the population, $E_{\max }$. (For interpretation of the references to colour in this figure legend, the reader is referred to the online version of the article.)

less effective at improving SSB-per-recruit and reducing bias in female:male sex ratio for the species than spawning reserves. The limited benefits of spawning reserves for $S$. sutor stemmed from (1) the change in catchability occurring with spawning aggregation formation, which is low for $S$. sutor relative to many other aggregative populations; and (2), to a lesser extent, from the life-history traits of the species (short life, rapid growth). Implementing normal residence reserves, which target juveniles and non-spawning adults, leads to a substantial increase in the number of $S$. sutor individuals surviving to the age of sexual maturity, resulting in an improvement in the SSB and exploitable biomass of the species (Grüss and Robinson 2015).

Grüss and Robinson (unpubl. results) used Grüss and Robinson (2015)'s model to examine the impacts of implementing marine reserves versus gear measures that increase the size of recruitment of $S$. sutor into the trap fishery of the main granitic islands from around $16.2 \mathrm{~cm}$ to $23 \mathrm{~cm}$ (size at sexual maturity). This additional work demonstrated that simulated gear measures are overall more effective at providing conservation benefits for $S$. sutor than spatial management measures (Figs. 4a and 4b), and significantly more beneficial to fisheries (Figs. 4c and 4d). Grüss and Robinson's findings highlight the need to weigh the value of MPAs against that of non-spatial management options.

\subsubsection{Targeted MPAs in temperate regions}

During the last three-four years, five modelling studies examined the conservation and fisheries effects of targeted MPAs for temperate migratory fish populations (Edwards and Plaganyi 2011; Hussein et al. 2011; Miethe et al. 2011; Grüss 2012; Rijnsdorp et al. 2012).

Edwards and Plaganyi (2011) and Grüss (2012) devised age-structured, population models to investigate the long-term 
consequences of targeted marine reserves for South African hakes (the deep water Cape hake, Merluccius paradoxus, and the shallow-water Cape hake, Merluccius capensis), whose juveniles and young adults undergo ontogenetic migrations and whose spawning and nursery areas are both relatively extensive and partially overlap. According to recent stock assessments, South African populations of M. paradoxus and $M$. capensis are, respectively, overexploited and in a relatively healthy state (Rademeyer et al. 2008; Rademeyer and Butterworth 2013). Edwards and Plaganyi (2011)'s model focuses on the effects of marine reserves on the mean age, SSB and recruitment of $M$. paradoxus and the exploitable biomass of the species for the offshore trawl fleet. This model is made of two patches (one patch with a majority of juveniles and one patch with a majority of adults) with implicit migrations of fishes between patches, and it has an annual time step.

Grüss (2012)'s modeling study explored the impacts of protecting preferentially the fishable juveniles or large adults of M. paradoxus on the mean age and SSB of both $M$. paradoxus and M. capensis and the yields of the different fishing fleets that depend on South African hakes (offshore and inshore trawl and longline fleets). This model is spatiallystructured and has a monthly time step. In Grüss (2012)'s model, hake ontogenetic migrations are represented via migration matrices built using a Geographic Information System (GIS)-based submodel. Four successive ontogenetic migrations were simulated for each hake species in the GIS-based submodel. The probability of an individual hake migrating from one area to another during one of the ontogenetic migration events was based on rules that are a function of local bathymetry and alongshore direction.

Hussein et al. (2011) used the ISIS-FISH model (Pelletier and Mahévas 2005; Pelletier et al. 2009) to assess the consequences of seasonal no-take targeted MPAs versus non-spatial management measures (fishing effort reduction, increases in gillnet mesh size) for the biomass and fisheries yields of the overexploited white seabream (Diplodus sargus sargus) population of the French Catalan coast. This application of ISIS-FISH has a monthly time step and analyses the conservation and fisheries effects of management measures after 20 years of simulation. Ontogenetic migrations and migrations between normal residence areas and spawning areas were represented via seasonal migration rates defined from the literature and experts' opinion.

Miethe et al. (2011) developed an evolutionary stage- and spatially-structured, individual-based model to compare the evolutionary and fisheries effects of spawning and feeding marine reserves for theoretical temperate migratory fish populations with different migration patterns (oceanodromous populations, salmon (Salmo salar)-like anadromous populations and charr (Salvelinus alpinus)-like anadromous populations). This model has an annual time step and evaluates the longterm effects of targeted marine reserves on fisheries yields, fisheries-induced evolutionary changes in size at maturation and the evolution of site fidelity. Migration rates between areas depend on the relative size of the areas and on the evolution of site fidelity.

Finally, Rijnsdorp et al. (2012) constructed an age- and spatially-structured per-recruit model to investigate the long- term, equilibrium impacts of seasonal marine reserves protecting the spawning areas of overexploited flatfish species (sole (Solea solea) and/or plaice (Pleuronectes platessa)) in the North Sea. Fixing relative recruitment strength, the authors examined the effects of spawning area closures on the SSB and fisheries-induced evolution of sole, plaice and other flatfish species (turbot (Scophthalmus maximus) and brill (Scophthalmus rhombus)) and on the yields and revenues of flatfishdirected fisheries, as well as the consequences of spawning area closures for bycatch levels and trawling impact on the benthos. Spawning migrations are implicit in Rijnsdorp et al. (2012)'s model.

In a single-species context, the modelling studies conducted during the last three-four years generally demonstrated that spawning MPAs have limited or negative conservation and fisheries effects in temperate regions. These findings are consistent with earlier modelling studies (e.g., Pelletier and Magal 1996; Horwood et al. 1998; Drouineau et al. 2006; Dunlop et al. 2009). In general, spawning MPAs were found to have limited effects (Grüss 2012), no positive effect (Hussein et al. 2011) or negative effects (Edwards and Plaganyi 2011) on the SSB of temperate migratory fish populations, essentially due to fishing effort redistribution on juveniles. Furthermore, spawning MPAs did not produce fisheries benefits (Edwards and Plaganyi 2011; Hussein et al. 2011; Grüss 2012). Miethe et al. (2011) also showed that spawning area closures do not affect fisheries-induced evolution in maturation size, because they create a stage-dependent mortality pattern favouring the catch of mature fishes migrating to spawning areas over immature fishes staying behind.

By contrast, Rijnsdorp et al. (2012)'s results indicate that seasonal spawning marine reserves produce conservation and fisheries benefits overall in a single-species context. Spawning area closures implemented for sole and/or plaice improved the SSB of these species. A spawning area closure for plaice also lessened fisheries-induced evolutionary changes in plaice size at maturation, due to a reduction of the fishing mortality on the older ages. Conversely, a spawning area closure for sole increased fisheries-induced evolutionary changes in sole size at maturation, though this effect was small. Finally, spawning area closures did not affect fisheries yields but increased the revenues made from the species targeted by spatial protection efforts, through this was due to the higher price of the landed fishes outside the spawning period which had a better condition than spawning fishes. All these results did not differ when evaluated at the levels of fishing efforts currently applied to flatfish or at levels of fishing effort producing Maximum Sustainable Yields (Rijnsdorp et al. 2012).

Still in a single-species context, recent modelling studies concurred on the conservation and fisheries benefits of protecting the juveniles of temperate migratory fish populations (Edwards and Plaganyi 2011; Hussein et al. 2011; Miethe et al. 2011; Grüss 2012). Both Edwards and Plaganyi (2011) and Grüss (2012) demonstrated that fishing the older section of the $M$. paradoxus population while protecting the younger individuals increase the mean age of the population and its SSB. In Grüss (2012), this improvement in SSB led to a considerable increase of the yields of $M$. paradoxus for the longline fleet, which only targets large adults. By contrast, the 
offshore trawl fleet targets both juveniles and adults, and the loss of harvestable biomass for this fleet due to MPA creation was not offset by an increase in SSB. Hussein et al. (2011)'s results indicate that seasonal no-take nursery MPAs, increases in gillnet mesh size and fishing effort reduction all lead to a considerable enhancement in both seabream biomass and fisheries yields. However, fishing effort reduction resulted in higher conservation and fisheries benefits than gear measures and nursery MPAs. This is especially true for the recreational fleet, which targets smaller and younger individuals than other seabream-directed fleets (Hussein et al. 2011). Miethe et al. (2011) found that protecting the feeding areas of a salmon-like anadromous population, where only adults migrate to spawning grounds, reduce fisheries-induced evolution in maturation size but also increase site fidelity, thereby limiting spillover and, consequently, fisheries yields. By contrast, protecting the feeding areas of an oceanodromous or of a charr-like anadromous population, where both adults and juveniles migrate to spawning grounds, can lead to both evolutionary protection and increased fisheries yields (Miethe et al. 2011).

Rijnsdorp et al. (2012) and Grüss (2012) also analysed the effects of targeted MPAs implemented for temperate migratory fish populations on mixed fisheries and the ecosystem. These supplementary analyses revealed that the benefits of targeted MPAs are more limited in a mixed fisheries and ecosystem context. Seasonal spawning area closures for flatfish populations had a mix of positive and negative impacts (Rijnsdorp et al. 2012). A spawning area closure for plaice increased the SSB of turbot and brill and decreased bycatch levels, but slightly decreased the SSB of sole and increased the trawling impact on the benthos. A spawning area closure for sole slightly reduced the trawling impact on the benthos, but decreased the SSB and revenues of other flatfish species (Rijnsdorp et al. 2012). Grüss (2012) found that, when fishing effort is redistributed and juveniles of $M$. paradoxus are preferentially targeted by spatial protection efforts, the SSB of $M$. capensis decreases slightly to moderately and the total hake yields of the longline fleet are only moderately increased, whereas other hake-directed fleets incur losses in total hake yields. For the other MPA scenarios examined, the SSB of M. capensis was relatively unchanged or moderately increased, while all fishing fleets incurred losses in total hake yields (Grüss 2012).

\subsection{Can MPAs benefit highly migratory fish populations and the fisheries targeting them?}

In recent years, for the first time in the history of MPA modelling, two studies investigated the conservation and fisheries effects of MPAs for highly migratory fish populations (Dueri and Maury 2013; Sibert et al. 2012).

\subsubsection{MPA effects for skipjack tuna in the Indian Ocean}

Dueri and Maury (2013) used APECOSM-E (ApexPredator-Ecosystem-Model - Estimation) to explore the effects of MPAs on the SSB and fisheries yields of skipjack tuna (Katsuwonus pelamis) population of the Indian Ocean and its fisheries. APECOSM-E is a size-structured, dynamic population model with a monthly time step, structured in three spatial dimensions (Dueri et al. 2012). K. pelamis belong to those highly migratory species that do not follow clear spawning or feeding migration patterns and exhibit large nomadic movements within habitat preferences (Stequert and Ramcharrum 1996). Thus, it is difficult to implement the targeted MPA approach for this species. In APECOSM-E, movements of $K$. pelamis were modelled using an advectiondiffusion scheme and partly depended on a three-dimensional habitat function which is defined from fields of temperature, oxygen and food provided by the coupled bio-physical model NEMO-PISCES (Aumont and Bopp 2006). Empirical evidence suggests that the $K$. pelamis population of the Indian Ocean is overexploited at present (IOTC 2010).

Dueri and Maury (2013) ran the APECOSM-E model from the early 1980 s to the year 2030 under alternative MPA scenarios (starting from 2010). The effects of two different year-round, no-take MPAs were examined: the existing Chagos Island MPA (Koldewey et al. 2010); and a hypothetical Western Indian Ocean MPA covering a substantial amount of the area where habitat is favourable to K. pelamis and the species is currently exploited (around one third of the Western Indian Ocean).

APECOSM-E predicted that the Chagos Island MPA has virtually no effect on $K$. pelamis and its fisheries because: (1) the closed area is small compared to the spatial scale of $K$. pelamis nomadic movements; and (2) K. pelamis undertakes seasonal migrations out of the MPA as a result of seasonallychanging habitat conditions. By contrast, the Western Indian Ocean MPA had a considerable effect on the fishing mortality of $K$. pelamis and succeeded in stabilising the SSB of the species, but resulted in decreases in fisheries yields. Although a loss in fisheries yields occurred over the period 2010-2030 with the Western Indian Ocean MPA, declines in fisheries yields over the period 2010-2030 were more pronounced in the absence of MPAs (Dueri and Maury 2013).

\subsubsection{MPA effects for bigeye tuna in the Western Central Pacific Ocean}

Sibert et al. (2012) applied the spatial ecosystem and population dynamics model (SEAPODYM) of tuna population dynamics and fisheries (Lehodey et al. 2008) to assess the impacts of seasonal, partial-take MPAs on the biomass and fisheries yields of the bigeye tuna (Thunnus obsesus) population of the Western Central Pacific Ocean. SEAPODYM is a three-dimensional, age-structured, dynamic population model similar to APECOSM-E, which has a monthly time step and covers the whole Pacific Ocean. In SEAPODYM, tuna migrations and nomadic movements are influenced by threedimensional fields of temperature, currents, dissolved oxygen and primary production and by euphotic depth, all of which are provided by the coupled bio-physical model NEMO-PISCES (Aumont and Bopp 2006). The T. obsesus population of the Western Central Pacific Ocean belongs to those highly migratory populations that follow clear spawning and feeding migration patterns (Kaplan et al. 2014). 2011 assessments for 
T. obesus indicated that the species may be overexploited at present (Davies et al. 2011).

Ten different management scenarios were tested in Sibert et al. (2012) over the period 1980-2003. The empirical spatial catch profiles for the fleets targeting adults of T. obesus (longline fleets) or harvesting the species incidentally (purse-seine fleets, which target $K$. pelamis) for the year 1980 were used to initialise SEAPODYM. The spatial management scenarios tested consisted in: (1) closing two high-seas enclaves in the West Central Pacific Commission convention area (implemented in the real world since 2009; Pala 2010) to the purseseine fleets; (2) and/or closing additional high-seas waters of the convention areas to the purse-seine and/or longline fleets; or (3) closing no area to fishing. When no MPA was implemented, (1) purse-seine effort was reduced by the amount that would have been lost in the closed areas; or (2) purse-seine effort associated with fishing aggregation devices (PS-FAD effort) was prohibited in the convention area and shifted to "free" schools. (Bycatch of juveniles of T. obesus associated with PS-FAD effort is considerably high).

Sibert et al. (2012)'s results show that excluding purseseiners from high-sea waters produces very small conservation benefits, and can even decrease T. obesus biomass if purseseine fishing effort is redistributed. By contrast, substantial increases in $T$. obesus biomass were obtained with management measures that control fishing mortality on both juveniles and adults through, respectively, the prohibition of FADs in the purse-seine fishery and the closure of spawning areas to longline fleets (under the so-called "F2SL" scenario). This finding confirms that MPAs are more effective at improving biomasses when used in combination with other management measures controlling fishing mortality (Sibert et al. 2012). However, substantial increases in biomass under the F2SL scenario came at the expense of decreases in yields for both the purse-seine and longline fisheries. Sibert et al. (2012) estimated the cost in lost yields under the F2SL scenario over a 24-year simulation period to be roughly equivalent to the current annual yield of $K$. pelamis by the purse-seine fishery and twice the current annual yield of T. obesus by the longline fishery.

\subsection{To which extent does variability of fish movement affect MPA effects?}

\subsubsection{Impacts of behavioural polymorphism on MPA effects}

In the individual-based model of Babcock et al. (2012) introduced in Section 3.1.1, simulations were based on the results of acoustic telemetry and census studies. Populations of snapper were seeded into cells within coastal domains including a marine reserve and fished areas or into a completely unfished coastal domain. Four movement behaviour categories encompassing the range of observed snapper activityrange patterns were defined. The behaviour of each individual snapper and the location of its centre of activity determined the fraction of time that individuals spent in protected and non-protected areas and, consequently, their mortality rates. Snappers spent a higher fraction of the time in the model cell where they recruited than in any other cell. Moreover, in
Babcock et al. (2012)'s model, only a fraction of snappers migrated to offshore spawning sites (that are open to fishing) from April to September and then returned to the model domains between October and January, while the rest of the snapper population stayed in model domains year-round.

Babcock et al. (2012) found difference in density-perrecruit between protected and non-protected areas was more sensitive to variations in the proportion of fish that displayed restricted versus expanded activity ranges and to the proportion of migratory fishes than to variations in sources of mortality. These results highlight the absolute need to account for behavioural polymorphism in applied MPA models when disparate movement behavioural modes exist in the real world, so as to adequately capture MPA impacts and ensure the reliability and efficiency of closed areas (Babcock et al. 2012).

\subsubsection{Impacts of straying on MPA effects}

Results of Grüss et al. (2011b) provide benchmarks on the use and functioning of MPAs for fish populations that move within a home range or undertake nomadic movements, but they also serve as a useful baseline for evaluating the potential consequences of MPAs for migratory fish populations. For tropical reef fish populations forming transient spawning aggregations, Grüss et al. (2011b)'s study provides insights into the potential impacts of spawning-site fidelity, or lack thereof ("straying"), on the effects of spawning reserves. Indeed, the fidelity of an aggregative population to specific spawning sites ensures that a fraction of the population will be offered full protection by spawning reserves. On the other hand, straying exposes individuals targeted for protection to fishing, similarly to fish movement within a home range. Therefore, Grüss et al. (2011b)'s results suggest that fishing effort displacement may considerably reduce the conservation and fisheries benefits of spawning reserves when study aggregation-forming populations show low spawning-site fidelity, whereas it may have only minor effects for aggregative populations that are faithful to specific spawning sites.

However, Grüss et al. (2014c) found that spawning-site fidelity or straying did not significantly affect the conservation and fisheries effects of spawning reserves protecting aggregation-forming populations. This result stems from the fact that closing spawning aggregation sites to fishing does not eliminate all fishing mortality on reserve individuals. As a result, the total mortality rate of individuals using protected spawning sites is quite similar to that of individuals using fished spawning sites, and these two mortality rates are relatively close to the average mortality rate of individuals that are unfaithful to spawning sites. These weak differences in mortality rates produce relatively small differences in results with and without spawning-site fidelity and, consequently, the effects of spawning area closures are predominantly determined by the fraction of spawning sites that is protected (Grüss et al. 2014c).

\section{Discussion}

\subsection{What we recently learnt}

There exists a diversity of adult and juvenile movement patterns in MPA systems, as reviewed in Grüss et al. (2011a). 
MPA modelling studies conducted during the last three-four years essentially considered movement in a home range, nomadic movements, behavioural polymorphism, ontogenetic migrations and spawning migrations. These different patterns of fish movement take place at different spatial and temporal scales and, therefore, expose mobile fish populations to fishing in different ways. Recent modelling studies showed that MPAs can be beneficial to overexploited mobile fish populations under a certain number of conditions, and to the fisheries targeting these fish populations under a very limited number of conditions (Table 2).

Recent modelling studies demonstrated that fish movement has a strong negative impact on the conservation effects of MPAs by exposing the reproductive capacity of the "MPA population" to fishing (Fig. 2b; Grüss et al. 2011b; Babcock et al. 2012). Given that fishing-the-line and fishing effort displacement typically occur in the real world, MPAs should be several times larger than fish movement spatial scales to offer effective protection to MPA individuals (Grüss et al. 2011b) and to ensure that the MPA population resembles more to an unfished population than to a fished population so as to improve fish egg-production capacity at a regional level (Babcock et al. 2012). The conservation effects of MPAs are sensitive to variations in the proportion of fish displaying restricted versus expanded activity ranges and to variations in the proportion of resident versus migratory fish (Babcock et al. 2012). Therefore, behavioural polymorphism should absolutely be considered in applied MPA models and at the time of MPA design when it exists in the real world. Moreover, in practice, MPAs generally cover a relatively small fraction of the total habitat area of fish populations. Based on Grüss et al. (2011b) and Grüss (unpubl. results), this suggests that, in most practical cases, spillover benefits only fishers operating close to closed area borders and recruitment subsidy has greater potential to improve overall fisheries yields than spillover.

In the case of migratory fish populations, modelling efforts undertaken over the recent years confirmed that MPAs designed to protect specific fractions of the population, i.e., targeted MPAs, can be effective in conservation terms without being extremely large (Edwards and Plaganyi 2011; Hussein et al. 2011; Miethe et al. 2011; Ellis and Powers 2012; Grüss 2012; Rijnsdorp et al. 2012; Grüss et al. 2014c; Grüss and Robinson 2015). Yet, these MPAs have to be significantly larger than fish movement spatial scales within targeted habitat. In the case of tropical aggregation-forming populations, in general, a large fraction of spawning sites should preferentially be closed to fishing, because catchability in spawning areas is extremely high and aggregation-forming populations generally have life-history traits conferring high vulnerability to fishing (slow life history, protogynous hermaphrodism). Recent models found that the closure of a large fraction of spawning areas is effective in conservation terms but will not produce fisheries benefits (Ellis and Powers 2012; Grüss et al. 2014c), though they suggest that fisheries yields may increase via recruitment subsidy in the long term and that further modelling studies are needed to investigate this (Grüss et al. 2014c). Variability in spawning-site fidelity has a negligible impact on spawning MPA effects since spawning area closures only moderately reduce the fishing mortality of adult individuals
(Grüss et al. 2014c). For those aggregation-forming populations whose catchability does not substantially increase with aggregation formation and whose life-history traits confer resilience to fishing (fast life history, gonochorism), normal residence MPAs should preferentially be implemented to generate significant conservation benefits as well as fisheries benefits via an increase in exploitable biomass due to an increase in population mean body size (Grüss and Robinson 2015).

In the case of temperate migratory fish populations, recent modelling studies indicate that nursery MPAs and/or any management measure that decreases juvenile fishing mortality (e.g., MPAs implemented in feeding areas, increase in mesh size) should be preferred over spawning MPAs (Edwards and Plaganyi 2011; Hussein et al. 2011; Miethe et al. 2011; Grüss 2012). In general, spawning MPAs have limited effects (Grüss 2012), no positive effect (Hussein et al. 2011) or negative effects (Edwards and Plaganyi 2011) on the SSB of temperate migratory fish populations essentially due to fishing effort redistribution on juveniles, and they do not affect fisheriesinduced evolution in maturation size (Miethe et al. 2011). An exception to these general patterns occurred in Rijnsdorp et al. (2012), where seasonal spawning area closures improved the SSB of the migratory flatfish populations targeted by spatial protection efforts and reduced the fisheries-induced evolutionary changes in the size at maturation of one the fish populations. However, these results were likely due to the short time frame where MPAs are implemented, such that fishing effort displacement did not considerably increase fishing pressure on flatfish juveniles. Moreover, all recent modelling studies are unanimous on the fact that spawning MPAs do not improve fisheries yields (Edwards and Plaganyi 2011; Hussein et al. 2011; Grüss 2012; Rijnsdorp et al. 2012). By contrast, nursery MPAs were found to significantly increase the mean age of temperate migratory fish populations and their biomass and, ultimately, to improve the recruitment levels of these fish populations and the yields of some fisheries (Edwards and Plaganyi 2011; Hussein et al. 2011; Grüss 2012). MPAs implemented in feeding areas, which protect both juveniles and adults of a migratory population, may also reduce fisheries-induced evolution in maturation size and enhance fisheries yields (Miethe et al. 2011).

However, the benefits of targeted MPAs for migratory fish populations appear more limited in a mixed fisheries and ecosystem context (Grüss 2012; Rijnsdorp et al. 2012). In this context, seasonal spawning MPAs for flatfish populations had a mix of positive and negative impacts rather than overall positive impacts (Rijnsdorp et al. 2012). In Grüss (2012), MPAs implemented in the nursery areas of $M$. paradoxus had a negative effect on the SSB of the $M$. capensis population, which was not targeted by spatial protection efforts and is not in an overexploitation state, while the total hake yields of only a limited number of fisheries were improved under specific conditions (Grüss 2012).

Highly migratory exploited fish populations have received attention in MPA modelling studies only during the last two to three years (Sibert et al. 2012; Dueri and Maury 2013). Dueri and Maury (2013)'s study showed that, in the case of a highly migratory populations that do not follow clear migration patterns and exhibit large nomadic movements within 
habitat preferences, large-scale MPAs such as Chagos Island no-take MPA have virtually no impact, while a giant MPA covering around one third of the Western Indian Ocean would have positive conservation effects at the expense of reductions in fisheries yields. Sibert et al. (2012) found that, in the case of highly migratory populations following clear spawning and feeding migration patterns, giant targeted MPAs covering entire high-seas territories have positive conservation effects under certain conditions (e.g., when supplemented with specific management measures) but decrease fisheries yields. The establishment of giant MPAs aimed at protecting highly migratory fish populations is likely to be impractical (Hobday et al. 2011; Rice and Houston 2011), and such MPAs may not improve fisheries yields, which indicates that closed areas may not be a pertinent management tool for highly migratory fish species.

\subsection{Where we should be going}

The present review revealed that significant modelling efforts have been undertaken during the last three to four years, which have considerably deepened our knowledge of the conservation and fisheries effects of closed areas for mobile fish populations. However, in view of the diversity of fish movement patterns in MPAs systems and current dynamics in resource management, it is clear that more modelling studies are needed to fully understand the impacts of closed areas for mobile exploited fish populations and the fisheries depending on these populations, and to be able to implement pertinent and efficient MPAs by the year 2020, for which conservation targets have been set (CBD 2010; Wood 2011; Spalding et al. 2013; Halpern 2014). Avenues for future research include: (1) the consideration of the diversity of density-independent and density-dependent fish movements in MPA models; (2) improvements in the representation of fish movement in MPA modelling studies; (3) the investigation of the effects of "dynamic MPAs" on highly migratory fish populations and the fisheries targeting them; (4) the systematic evaluation of the effects of MPAs in relation to other management tools to find strategies that are most effective in meeting management objectives; (5) the consideration in biological MPA models of factors that have a significant influence on the impacts of closed areas in the real world: (i) the economic consequences of MPAs, i.e., their influence on fisheries revenues and costs; (ii) the degree of protection actually offered by closed areas; (iii) the many different objectives associated with the establishment of MPAs; (iv) the transient responses of exploited fish populations and fisheries yields to MPA creation; and (v) the degree of compliance of fishers.

The modelling studies I reviewed consider only densityindependent patterns of adult and juvenile movement, with the exception of Sibert et al. (2012) and Dueri and Maury (2012), who related the movements of tropical tunas to habitat quality and prey density. There exists a range of patterns of densitydependent movements in MPA systems, including densitydependent spillover, density-dependent spill-in, and movements arising from predator-prey interactions (see Grüss et al. 2011a for a review). Furthermore, changes in habitat quality can influence the direction and extent of fish movements in many different ways (e.g., Horwood et al. 2006; Van Keeken et al. 2007; Parsons et al. 2010; Johansen et al. 2013). The diversity of patterns of fish movement and fish movement behaviour in MPA systems has not been given full consideration in MPA models because some of these patterns have a negligible impact on MPA effects in certain contexts, or because it is unclear how to correctly represent these patterns. Modelling studies assessing how and how well the different existing patterns of fish movement and fish movement behaviour affect the functioning of closed areas are needed to be able to represent ecological connectivity adequately in applied MPA models and to create effective MPA networks for mobile exploited fish populations and their fisheries (see detailed discussions in Grüss et al. 2011a).

The representation of density-independent fish movement in MPA modelling studies has become more and more sophisticated. For example, Grüss et al. (2011b) and Moffitt et al. (2013) modelled fish movement within a home range in their spatially-structured metapopulation models using a Laplacian distribution and a Gaussian distribution, respectively. Babcock et al. (2012) used the results of acoustic telemetry and census studies to parameterise behavioural polymorphism in their spatially-structured, individual-based model for New Zealand snapper. However, there is a need for increased collaboration between modellers and empiricists to offer a realistic representation of fish movement in applied MPA models (White et al. 2011; Grüss et al. 2014a). For instance, modellers could make more use of the results of both acoustic and satellite telemetry to properly parameterise the movements of fish populations both moving within a home range and undertaking seasonal migrations (Grüss et al. 2011a). In situations where empirical movement studies are missing, modellers could use distribution maps constructed from statistical habitat models to produce connectivity matrices (Drexler and Ainsworth 2013; Grüss et al. 2014b).

Because the implementation of giant MPAs aimed at protecting highly migratory fish populations is likely impractical (Hobday et al. 2011; Rice and Houston 2011) and may not improve fisheries yields (Sibert et al. 2012; Dueri and Maury 2013), some authors recently proposed the establishment of "dynamic" MPAs following highly migratory fish populations in space and time (e.g., Norse et al. 2005; Game et al. 2009; Hobday et al. 2011). Dynamic MPAs are closed areas whose borders are adjusted in response to changes in the habitat features that are known to influence the movements of highly migratory fishes (e.g., the strength and direction of oceanic currents, sea surface isotherms; Game et al. 2009). The efficacy and feasibility of dynamic MPAs has only begun to be explored, although initial results on the use of dynamic spatial zoning to manage southern bluefin tuna (Thunnus maccoyii) yields in eastern Australia are relatively promising (Hobday et al. 2010). Modelling studies are needed to examine the potential conservation and fisheries effects of dynamic MPAs in diverse regions.

Some of the recent modelling studies I reviewed in the present study compared the effects of MPAs to those of nonspatial management tools and found that, in certain contexts, management measures such as fishing effort reduction (Hussein et al. 2011) or gear measures increasing selectivity 
for larger fish (Grüss and Robinson, unpubl. results) are more appropriate than MPAs for the conservation and sustainable exploitation of mobile fish populations. These findings underscore the need to systematically gauge the potential impacts of MPAs relative to those of other management options to ultimately implement those measures that are most effective at reaching management objectives (Kaiser 2005; Agardy et al. 2011). Moreover, the recent modelling studies that I reviewed all agree that fishing effort displacement considerably reduce the benefits of MPAs for mobile exploited fish populations and their fisheries (Grüss et al. 2011b, 2014c; Hussein et al. 2011; Ellis and Powers 2012; Grüss 2012; Sibert et al. 2012). This highlights that any type of MPAs is unlikely to be work well in isolation and must be complemented by other management measures controlling fishing effort or fishing gear efficiency (e.g., Agardy et al. 2011; Hussein et al. 2011; Ellis and Powers 2012; Sibert et al. 2012; Ban et al. 2014).

Even though specific models are intended to examine the economic implications of MPAs (i.e., the "bioeconomic MPA models"), biological MPA models should inform stakeholders about the basic economic consequences of implementing closed areas for mobile exploited fish populations. This has seldom been done and should be changed. MPAs may have important impacts on fisheries revenues through fish prices, essentially due to a shift in the size composition of landings (Holland 2000; Roberts and Sargant 2002; Alban et al. 2008; Rijnsdorp et al. 2012). For example, Rijnsdorp et al. (2012) found that flatfish spawning MPAs in the North Sea did not improve fisheries yields, but enhanced fisheries revenues because of the higher price of fishes landed outside the spawning period that had a better condition than spawning fishes. This result suggests that, in many cases, ignoring the effects of closed areas on fisheries revenues may underestimate their benefits to fisheries. By contrast, various economic factors, such as increased travel costs, are likely to significantly reduce the potential benefits of MPAs to fisheries (Alban et al. 2008; Ban and Klein 2009). Moreover, biological MPA models often ignore fishers' movements other than fishing effort displacement, while fishers' behaviour has a considerable influence on yields (e.g., Kellner et al. 2007; Botsford et al. 2009; Grüss et al. 2011a). Future applied biological modelling studies should systematically consider fishers' movement in response to spillover and other factors (e.g., travel costs) (Holland 2000; Pelletier and Mahévas 2005; Botsford et al. 2009).

MPAs in the real world are generally far from being only no-take zones as usually represented in models, but rather consist in a superposition of different zones, with, in general, a central zone where all human extractive activities are prohibited, a "buffer zone" where extractive activities are highly restricted, and a peripheral zone where regulations of activities are less restrictive (Claudet 2011; Mesnildrey et al. 2013). Thus, networks of MPAs often are "mosaics" of zones under different regulations (Douvere 2008; Halpern et al. 2010; Kelaher et al. 2014). This complex organisation of MPAs may considerably reduce the degree of protection offered to mobile fish species and, therefore, may likely reduce the conservation benefits of closed areas and alter the fisheries effects of MPAs that are currently predicted by most MPA models.
Future applied MPA models should offer a representation of MPA networks closer to reality to accurately predict the impacts of spatial protection measures for mobile exploited fish populations and the fisheries that depend on them.

Furthermore, there is a growing range of objectives associated with the establishment of MPAs that extend beyond the conservation of specific fish populations and fisheries welfare, including marine biodiversity, reduction of pollution and habitat destruction, tourism and human well-being (Halpern et al. 2010; Claudet 2011; Ban et al. 2014). Therefore, applied modelling studies should increasingly shift their focus from MPAs to comprehensive "marine spatial planning" and "ocean zoning", which account for both species conservation and multiple-use objectives (Douvere 2008; Halpern et al. 2010; Agardy et al. 2011; Collie et al. 2013). The need to achieve other objectives in addition to species conservation and fisheries welfare will introduce trade-offs which may significantly alter the benefits of closed areas that are currently predicted by MPA models for mobile fish species and their fisheries (Rassweiler et al. 2014).

The modelling studies conducted during the last three-four years generally studied only the long-term, equilibrium impacts of MPAs for mobile fish populations and their fisheries, with the exception of Sibert et al. (2012), Dueri and Maury (2013) and Moffitt et al. (2013) (Table 2). Using a dynamic, spatially-structured population model, Moffitt et al. (2013) showed that the largest MPA conservation effects should be expected after two generations (fish lifespans) have passed since the establishment of closed areas, and confirmed that it takes a long time for mobile fish populations to build up with MPAs. There is a need for studies using dynamic MPA models of the type of ISIS-FISH or SEAPODYM to evaluate the extent of decreases in fisheries yields made from specific mobile fish populations in the short term, and the time needed for the biomass of these populations to consistently improve with MPAs so as to eventually increase fisheries yields through spillover and recruitment subsidy.

Finally, MPA models typically assume that closed areas are perfectly enforced (but see, e.g., Little et al. 2007, 2009 and Le Quesne 2009). By contrast, limited or non-existent enforcement of closed areas is frequent in the real world, while enforcement was identified as one of the key factors to conservation success in a recent large-scale review of MPA performance (Edgar et al. 2014). Future applied MPA models should account for the probability of poaching of mobile fish individuals when they are within protected area borders either through the use of an infringement rate (e.g., Little et al. 2007, 2009) or through a sophisticated representation of fishers' behaviour (e.g., Byers and Noonburg 2007).

\section{Conclusion}

Modelling studies conducted during the last three to four years have considerably improved our knowledge of the impacts of closed areas for mobile exploited fish populations and their fisheries. These studies showed that MPAs aimed at protecting mobile species may have positive conservation effects under a relatively wide range of situations, but may generate long-term fisheries benefits only under a very limited set of 
conditions. Strategies producing both conservation and fisheries benefits were identified, which depend on fish movement patterns and numerous aspects of fish life history and fisheries dynamics. However, modelling efforts must be continued to determine the conditions under which MPAs may be beneficial for both species conservation and fisheries on a case-by-case basis. Moreover, modelling studies should systematically assess the effects of MPAs in relation to other management tools to find strategies that are most effective in meeting management objectives. They should also offer a more realistic representation of the real world, in particular by progressively shifting their focus from marine reserves to marine spatial planning and ocean zoning. Another important avenue for research is the investigation of the impacts of " $\mathrm{dy}$ namic" MPAs that follow highly migratory fish populations in space and time. We are close to the year 2020, for which conservation targets have been set (10\% of the world's ecological regions in MPAs; CBD 2010), so much more resources should be invested in MPA modelling rapidly.

Acknowledgements. I am grateful to Jan Robinson and David Kaplan for the numerous exchanges of thoughts I have had with them, and to Chris Koenig for his personal communication. I would like to thank the editor and two anonymous reviewers for their insightful comments on the manuscript, which significantly improved its scope and quality.

\section{Glossary}

Marine protected areas (MPAs): Zones where fishing activities and other human extractive activities are partially ("partialtake MPAs") or totally prohibited ("no-take MPAs" or "marine reserves"), year round or seasonally, except when these activities are performed for scientific purposes. A MPA system is defined as a system composed of MPA(s) and fished areas.

Spillover: Net movement of adult and/or juvenile biomass out of MPAs, linked to density-dependent and/or density independent fish movements. Spillover linked to migratory movements can lead to an increase in the exploitable biomass of a fish population via an increase in the mean body size of this population.

Bycatch: Incidental catch of marine organisms by fishing fleets when in pursuit of targeted species.

Oceanodromous populations: Fish populations that migrate within the ocean only.

Anadromous populations: Fish populations migrating from the sea to spawn in fresh water (e.g., salmons).

Fishing aggregation devices (FADs): Man-made objects that are used to attract migratory pelagic fishes such as tunas and billfishes. Usually, FADs consist of buoys or floats tethered to the sea bottom with concrete blocks. Schools of migratory fish populations that are not associated with FADs are referred to as "free" schools.

Ocean zoning: Authoritative regulation of different human activities in different parts of a marine region.
Marine spatial planning: Process of analysing and allocating the spatial and temporal distribution of human activities in marine regions to achieve ecological and socio-economic objectives.

\section{References}

Agardy T., Di Sciara G.N., Christie P., 2011, Mind the gap: Addressing the shortcomings of marine protected areas through large scale marine spatial planning. Mar. Policy 35, 226-232.

Agardy T.S., Bridgewater P., Crosby M.P., Day J., Dayton P.K., Kenchington R., Laffoley D., McConney P., Murray P.A., Parks J.E., et al., 2003, Dangerous targets? Unresolved issues and ideological clashes around marine protected areas. Aquat. Conserv. $13,353-367$.

Alban F., Appéré G., Boncoeur J., 2008, Economic analysis of Marine Protected Areas. A literature review. EMPAFISH Project Booklet $3,51 \mathrm{p}$.

Alemany D., Iribarne O.O., Acha E.M., 2013, Effects of a large-scale and offshore marine protected area on the demersal fish assemblage in the Southwest Atlantic. ICES J. Mar. Sci. 70, 123-134.

Alonzo S.H., Mangel M., 2004, The effects of size-selective fisheries on the stock dynamics of and sperm limitation in sex-changing fish. Fish. Bull. 102, 1-13.

Apostolaki P., Milner-Gulland E.J., McAllister M.K., Kirkwood G.P., 2002, Modelling the effects of establishing a marine reserve for mobile fish species. Can. J. Fish. Aquat. Sci. 59, 405-415.

Armstrong M.P., Dean M.J., Hoffman W.S., Zemeckis D.R., Nies T.A., Pierce D.E., Diodati P.J., McKiernan D.J., 2012, The application of small scale fishery closures to protect Atlantic cod spawning aggregations in the inshore Gulf of Maine. Fish. Res. $141,62-69$.

Attwood C.G., Bennett B.A., 1995, Modelling the effect of marine reserves on the recreational shore-fishery of the south-western cape, South Africa. South Afr. J. Mar. Sci. 16, 227-240.

Aumont O., Bopp L., 2006, Globalizing results from ocean in situ iron fertilization studies. Glob. Biogeochem. Cycles 20, GB2017, doi : 10.1029/2005GB002591.

Babcock R.C., Egli D.P., Attwood C.G., 2012, Incorporating behavioural variation in individual-based simulation models of marine reserve effectiveness. Environ. Conserv. 39, 282-294.

Ban N.C., Klein C.J., 2009, Spatial socioeconomic data as a cost in systematic marine conservation planning. Conserv. Lett. 2, 206-215.

Ban N.C., Maxwell S.M., Dunn D.C., Hobday A.J., Bax N.J., Ardron J., Gjerde K.M., Game E.T., Devillers R., Kaplan D.M., et al., 2014, Better integration of sectoral planning and management approaches for the interlinked ecology of the open oceans. Mar. Policy 49, 127-136.

Barr L.M., Possingham H.P., 2013, Are outcomes matching policy commitments in Australian marine conservation planning? Mar. Policy 42, 39-48.

Baskett M.L., Levin S.A., Gaines S.D., Dushoff J., 2005, Marine reserve design and the evolution of size at maturation in harvested fish. Ecol. Appl. 15, 882-901.

Bijoux J.P., Dagorn L., Berke G., Cowley P.D., Soria M., Gaertner J.-C., Robinson J., 2013, Temporal dynamics, residency and site fidelity of spawning aggregations of a herbivorous tropical reef fish Siganus sutor. Mar. Ecol. Prog. Ser. 475, 233-247.

Block B., Jonsen I., Jorgensen S., Winship A., Shaffer S., Bograd S., Hazen E., Foley D., Breed G., Harrison A.L., et al., 2011, Tracking apex marine predator movements in a dynamic ocean. Nature 475, 86-90. 
Bohnsack J.A., Ault J.S., Bannerot S.P., Causey B., 2004, Why have no-take marine protected areas. Am. Fish. Soc. Symp. 42, 185-193.

Botsford L.W., Brumbaugh D.R., Grimes C., Kellner J.B., Largier J., O'Farrell M.R., Ralston S., Soulanille E., Wespestad V., 2009, Connectivity, sustainability, and yield: bridging the gap between conventional fisheries management and marine protected areas. Rev. Fish Biol. Fish. 19, 69-95.

Botsford L.W., Hastings A., Gaines S.D., 2001, Dependence of sustainability on the configuration of marine reserves and larval dispersal distance. Ecol. Lett. 4, 144-150.

Bradbury I.R., Laurel B.J., Robichaud D., Rose G.A., Snelgrove P.V.R., Gregory R.S., Cote D., Windle M.J.S., 2008, Discrete spatial dynamics in a marine broadcast spawner: Re-evaluating scales of connectivity and habitat associations in Atlantic cod (Gadus morhua L.) in coastal Newfoundland. Fish. Res. 91, 299-309.

Brooks C.M., 2013, Competing values on the Antarctic high seas: CCAMLR and the challenge of marine-protected areas. Polar J. 3, 277-300.

Byers J.E., Noonburg E.G., 2007, Poaching, enforcement, and the efficacy of marine reserves. Ecol. Appl. 17, 1851-1856.

CBD, 2010, Decision X/2: the strategic plan for biodiversity 20112020 and the Aichi biodiversity target. Convention on Biological Diversity, CBD, Nagoya, Japan.

Chown S.L., 2013, Antarctic treaty system past not predictive. Science 339, 141-141.

Claudet J., 2011, Marine protected areas: a multidisciplinary approach. Cambridge, UK, Cambridge University Press.

Coleman F.C., Koenig C.C., Collins L.A., 1996, Reproductive styles of shallow water groupers of the northeastern Gulf of Mexico and the consequences of fishing spawning aggregations. Environ. Biol. Fishes 47, 129-141.

Collie J.S., Adamowicz W.L., Beck M.W., Craig B., Essington T.E., Fluharty D., Rice J., Sanchirico J.N., 2013, Marine spatial planning in practice. Estuar. Coast. Shelf Sci. 117, 1-11.

Cury P., Pauly D., 2013, Mange tes méduses ! Réconcilier les cycles de la vie et la flèche du temps. Paris, Editions Odile Jacob.

Davies N., Hoyle S.D., Harley S.J., Langley A.D., Hampton J., 2011, Stock assessment of bigeye tuna in the western and central Pacific Ocean. WCPFC-SC7-2011/SA-WP-02, 133 p.

DeMartini E.E., 1993, Modeling the potential of fishery reserves for managing Pacific coral reef fishes. Fish. Bull. 91, 414-427.

Domeier M.L., Colin P.L., 1997, Tropical reef fish spawning aggregations: defined and reviewed. Bull. Mar. Sci. 60, 698-726.

Douvere F., 2008, The importance of marine spatial planning in advancing ecosystem-based sea use management. Mar. Policy 32, $762-771$.

Drexler M., Ainsworth C.H., 2013, Generalized Additive Models Used to Predict Species Abundance in the Gulf of Mexico: An Ecosystem Modeling Tool. PloS One 8, e64458.

Drouineau H., Mahévas S., Pelletier D., Beliaeff B., 2006, Assessing the impact of different management options using ISIS-Fish: the French Merluccius merluccius-Nephrops norvegicus mixed fishery of the Bay of Biscay. Aquat. Living Resour. 19, 15-29.

Dueri S., Faugeras B., Maury O., 2012, Modelling the skipjack tuna dynamics in the Indian Ocean with APECOSM-E: Part 1. Model formulation. Ecol. Model. 245, 41-54.

Dueri S., Maury O., 2013, Modelling the effect of marine protected areas on the population of skipjack tuna in the Indian Ocean. Aquat. Living Resour. 26, 171-178.

Dunlop E.S., Baskett M.L., Heino M., Dieckmann U., 2009, Propensity of marine reserves to reduce the evolutionary effects of fishing in a migratory species. Evol. Appl. 2, 371-393.
Edgar G.J., 2011, Does the global network of marine protected areas provide an adequate safety net for marine biodiversity? Aquat. Conserv. Mar. Freshw. Ecosyst. 21, 313-316.

Edgar G.J., Stuart-Smith R.D., Willis T.J., Kininmonth S., Baker S.C., Banks S., Barrett N.S., Becerro M.A., Bernard A.T., Berkhout J., 2014, Global conservation outcomes depend on marine protected areas with five key features. Nature, doi:10.1038/ nature 13022 .

Edwards C.T.T., Plaganyi E.E., 2011, Protecting old fish through spatial management: is there a benefit for sustainable exploitation? J. Appl. Ecol. 48, 853-863.

Egli D.P., Babcock R.C., 2004, Ultrasonic tracking reveals multiple behavioural modes of snapper (Pagrus auratus) in a temperate no-take marine reserve. ICES J. Mar. Sci. 61, 1137-1143.

Ellis R.D., Powers J.E., 2012, Gag grouper, marine reserves, and density-dependent sex change in the Gulf of Mexico. Fish. Res. $115,89-98$.

Gaines S.D., Gaylord B., Largier J.L., 2003, Avoiding current oversights in marine reserve design. Ecol. Appl. 13, 32-46.

Gaines S.D., Lester S.E., Grorud-Colvert K., Costello C., Pollnac R., 2010, Evolving science of marine reserves: New developments and emerging research frontiers. Proc. Natl. Acad. Sci. 107, 18251-18255.

Game E.T., Grantham H.S., Hobday A.J., Pressey R.L., Lombard A.T., Beckley L.E., Gjerde K., Bustamante R., Possingham H.P., Richardson A.J., 2009, Pelagic protected areas: the missing dimension in ocean conservation. Trends Ecol. Evol. 24, 360-369.

Gell F.R., Roberts C.M., 2003, Benefits beyond boundaries: the fishery effects of marine reserves. Trends Ecol. Evol. 18, 448-455.

Gerber L.R., Botsford L.W., Hastings A., Possingham H.P., Gaines S.D., Palumbi S.R., Andelman S., 2003, Population models for marine reserve design: a retrospective and prospective synthesis. Ecol. Appl. 13, 47-64.

Gerber L.R., Heppell S.S., Ballantyne F., Sala E., 2005, The role of dispersal and demography in determining the efficacy of marine reserves. Can. J. Fish. Aquat. Sci. 62, 863-871.

Grüss A., 2012, Evaluation of the effectiveness of marine protected areas for mobile exploited fish populations and their fisheries: Modeling approaches. PhD thesis, University of Montpellier 2.

Grüss A., Robinson J., 2015, Fish populations forming transient spawning aggregations: Should spawners always be the targets of spatial protection efforts? ICES J. Mar. Sci., doi : 10.1093/icesjms/fsu139.

Grüss A., Kaplan D.M., Guénette S., Roberts C.M., Botsford L.W., 2011a, Consequences of adult and juvenile movement for Marine Protected Areas. Biol. Conserv. 144, 692-702.

Grüss A., Kaplan D.M., Hart D.R., 2011b, Relative impacts of adult movement, larval dispersal and harvester movement on the effectiveness of reserve networks. PloS One 6, e19960.

Grüss A., Robinson J., Heppell S.S., Heppell S.A., Semmens B.X., 2014a, Conservation and fisheries effects of spawning aggregation marine protected areas: what we know, where we should go and what we need to get there. ICES J. Mar. Sci., doi : 10.1093/icesjms/fsu038.

Grüss A., Drexler M., Ainsworth C.H., 2014b, Using delta generalized additive models to produce distribution maps for spatiallyexplicit ecosystem models. Fish. Res. 159, 11-24.

Grüss A., Kaplan D.M., Robinson J., 2014c, Evaluation of the effectiveness of marine reserves for transient spawning aggregations in data-limited situations. ICES J. Mar. Sci., 71, 435-449.

Guénette S., Lauck T., Clark C., 1998, Marine reserves: from Beverton and Holt to the present. Rev. Fish Biol. Fish. 8, 251-272. 
Guénette S., Pitcher T.J., 1999, An age-structured model showing the benefits of marine reserves in controlling overexploitation. Fish. Res. 39, 295-303.

Halpern B.S., 2014, Conservation: Making marine protected areas work. Nature 506, 167-168.

Halpern B.S., Lester S.E., McLeod K.L., 2010, Placing marine protected areas onto the ecosystem-based management seascape. Proc. Natl. Acad. Sci. 107, 312-317.

Halpern B.S., Warner R.R., 2003, Matching marine reserve design to reserve objectives. Proc. R. Soc. Lond. B Biol. Sci. 270, $1871-1878$.

Hart D.R., 2006, When do marine reserves increase fishery yield? Can. J. Fish. Aquat. Sci. 63, 1445-1449.

Hastings A., Botsford L.W., 2006, Persistence of spatial populations depends on returning home. Proc. Natl. Acad. Sci. 103, 6067-6072.

Heppell S.S., Heppell S.A., Coleman F.C., Koenig C.C., 2006, Models to compare management options for a protogynous fish. Ecol. Appl. 16, 238-249.

Hilborn R., Stokes K., Maguire J.J., Smith T., Botsford L.W., Mangel M., Orensanz J., Parma A., Rice J., Bell J., et al., 2004, When can marine reserves improve fisheries management? Ocean Coast. Manag. 47, 197-205.

Hobday A.J., Game E.T., Grantham H.S., Richardson A.J., 2011, Missing Dimension - Conserving the largest habitat on earth: protected areas in the pelagic ocean. In: Claudet J. (Ed.) Marine Protected Areas: A Multidisciplinary Approach, Cambridge, Cambridge University Press, pp. 347-372.

Hobday A.J., Hartog J.R., Timmis T., Fielding J., 2010, Dynamic spatial zoning to manage southern bluefin tuna (Thunnus maccoyii) capture in a multi-species longline fishery. Fish. Oceanogr. 19, 243-253.

Holland D.S., 2000, A bioeconomic model of marine sanctuaries on Georges Bank. Can. J. Fish. Aquat. Sci. 57, 1307-1319.

Holland D.S., Brazee R.J., 1996, Marine reserves for fisheries management. Mar. Resour. Econ. 11, 157-172.

Horwood J., O’Brien C., Darby C., 2006, North Sea cod recovery? ICES J. Mar. Sci. 63, 961-968.

Horwood J.W., Nichols J.H., Milligan S., 1998, Evaluation of closed areas for fish stock conservation. J. Appl. Ecol. 35, 893-903.

Hussein C., Verdoit-Jarraya M., Pastor J., Ibrahim A., Saragoni G., Pelletier D., Mahévas S., Lenfant P., 2011, Assessing the impact of artisanal and recreational fishing and protection on a white seabream (Diplodus sargus sargus) population in the northwestern Mediterranean Sea, using a simulation model. Part 2: Sensitivity analysis and management measures. Fish. Res. 108, 174-183.

Hutchinson N., Rhodes K.L., 2010, Home range estimates for squaretail coralgrouper, Plectropomus areolatus (Rüppell 1830). Coral Reefs 29, 511-519.

IOTC, 2010, Report of the 12th Session of the IOTC Working Party on Tropical Tunas. Victoria, Seychelles IOTC Doc IOTC-2010WPTT-R E.

Johannes R.E., 1998, The case for data-less marine resource management: examples from tropical nearshore finfisheries. Trends Ecol. Evol. 13, 243-246.

Johansen J.L., Messmer V., Coker D.J., Hoey A.S., Pratchett M.S., 2013, Increasing ocean temperatures reduce activity patterns of a large commercially important coral reef fish. Glob. Change Biol. 20, 1067-1074.

Jones N., 2011, Marine protection goes large. Nature News, doi : 10.1038/news.2011.292.
Kahui V., Alexander W.R.J., 2008, A bioeconomic analysis of marine reserves for Paua (Abalone) management at Stewart Island, New Zealand. Environ. Resour. Econ. 40, 339-367.

Kaiser M.J., 2005, Are marine protected areas a red herring or fisheries panacea? Can. J. Fish. Aquat. Sci. 62, 1194-1199.

Kaplan D.M., Botsford L.W., O'Farrell M.R., Gaines S.D., Jorgensen S., 2009, Model-based assessment of persistence in proposed marine protected area designs. Ecol. Appl. 19, 433-448.

Kaplan D.M., Chassot E., Amandé J.M., Dueri S., Demarcq H., Dagorn L., Fonteneau A., 2014, Spatial management of Indian Ocean tropical tuna fisheries: potential and perspectives. ICES J. Mar. Sci., doi : 10.1093/icesjms/fst233.

Kaplan D.M., Chassot E., Grüss A., Fonteneau A., 2010, Pelagic MPAs: The devil is in the details. Trends Ecol. Evol. 25, 62-63.

Kelaher B.P., Coleman M.A., Broad A., Rees M.J., Jordan A., Davis A.R., 2014, Changes in fish assemblages following the establishment of a network of no-take marine reserves and partiallyprotected areas. PloS One 9, e85825.

Kellner J.B., Tetreault I., Gaines S.D., Nisbet R.M., 2007, Fishing the line near marine reserves in single and multispecies fisheries. Ecol. Appl. 17, 1039-1054.

Kerwath S.E., Winker H., Götz A., Attwood C.G., 2013, Marine protected area improves yield without disadvantaging fishers. Nature Communications 4, 2347, doi : 10.1038/ncomms3347.

Koenig C.C., Coleman F.C., Collins L.A., Colin P.L., 1996, Reproduction in gag (Mycteroperca microlepis) (Pisces: Serranidae) in the eastern Gulf of Mexico and the consequences of fishing spawning aggregations. In: Biology, fisheries, and culture of tropical groupers and snappers: Proc. EPOMEX/ICLARM International Workshop on Tropical Snappers and Groupers, University of Campeche, Mexico, 26-29 October 1993.

Koldewey H.J., Curnick D., Harding S., Harrison L.R., Gollock M., 2010, Potential benefits to fisheries and biodiversity of the Chagos Archipelago/British Indian Ocean Territory as a no-take marine reserve. Mar. Pollut. Bull. 60, 1906-1915.

Le Quesne W.J., 2009, Are flawed MPAs any good or just a new way of making old mistakes? ICES J. Mar. Sci. 66, 132-136.

Le Quesne W.J.F., Codling E.A., 2009, Managing mobile species with MPAs: the effects of mobility, larval dispersal, and fishing mortality on closure size. ICES J. Mar. Sci. 66, 122-131.

Lehodey P., Senina I., Murtugudde R., 2008, A spatial ecosystem and populations dynamics model (SEAPODYM)-Modeling of tuna and tuna-like populations. Prog. Oceanogr. 78, 304-318.

Little L.R., Punt A.E., Mapstone B.D., Begg G.A., Goldman B., Ellis N., 2009, Different responses to area closures and effort controls for sedentary and migratory harvested species in a multispecies coral reef linefishery. ICES J. Mar. Sci. 66, 1931-1941.

Little L.R., Punt A.E., Mapstone B.D., Pantus F., Smith A.D.M., Davies C.R., McDonald A.D., 2007, ELFSim-A model for evaluating management options for spatially structured reef fish populations: An illustration of the "larval subsidy" effect. Ecol. Model. 205, 381-396.

Lubchenco J., Palumbi S.R., Gaines S.D., Andelman S., 2003, Plugging a hole in the ocean: the emerging science of marine reserves. Ecol. Appl. 13, S3-S7.

Madigan D.J., Baumann Z., Carlisle A.B., Hoen D.K., Popp B.N., Dewar H., Snodgrass O.E., Block B.A., Fisher N.S., 2014, Reconstructing transoceanic migration patterns of Pacific bluefin tuna using a chemical tracer toolbox. Ecology 95, 1674-1683.

Mesnildrey L., Gascuel D., Le Pape O., 2013, Integrating Marine Protected Areas in fisheries management systems: some criteria for ecological efficiency. Aquat. Living Resour. 26, 159-170. 
Miethe T., Dytham C., Dieckmann U., Pitchford J.W., 2010, Marine reserves and the evolutionary effects of fishing on size at maturation. ICES J. Mar. Sci. 67, 412-425.

Miethe T., Pitchford J., Dytham C., 2009, An individual-based model for reviewing marine reserves in the light of fisheries-induced evolution in mobility and size at maturation. J. Northwest Atl. Fish. Soc. 41, 151-162.

Miethe T., Pitchford J.W., Dytham C., 2011, Modelling the evolutionary effects of a coastal marine reserve on different ecological guilds of fish. J. Mar. Biol. Assoc. UK 91, 1369-1380.

Moffitt E.A., Botsford L.W., Kaplan D.M., O'Farrell M.R., 2009, Marine reserve networks for species that move within a home range. Ecol. Appl. 19, 1835-1847.

Moffitt E.A., White J.W., Botsford L.W., 2013, Accurate assessment of marine protected area success depends on metric and spatiotemporal scale of monitoring. Mar. Ecol. Prog. Ser. 489, $17-28$.

Murawski S.A., Wigley S.E., Fogarty M.J., Rago P.J., Mountain D.G., 2005, Effort distribution and catch patterns adjacent to temperate MPAs. ICES J. Mar. Sci. 62, 1150-1167.

Norse E.A., Crowder L.B., Cjerde K., Hyrenbach D., Roberts C.M., Safina C., Soule M.E., 2005, Place-Based Ecosystem Management in the Open Ocean. In: Norse E.A., Crowder L.B. (Eds.) Marine Conservation Biology: The Science of Maintaining the Sea's Biodiversity. Island Press, Washington, DC, pp. 302-325.

Pala C., 2009, Protecting the last great tuna stocks. Science 324, 1133-1133.

Pala C., 2010, Islands champion tuna ban. Nature 468, 739-740.

Pala C., 2013, Giant marine reserves pose vast challenges. Science $339,640-641$.

Palumbi S.R., 2004, Marine reserves and ocean neighborhoods: the spatial scale of marine populations and their management. Annu. Rev. Environ. Resour. 29, 31-68.

Parsons D.M., Babcock R.C., Hankin R.K.S., Willis T.J., Aitken J.P., O'Dor R.K., Jackson G.D., 2003, Snapper Pagrus auratus (Sparidae) home range dynamics: acoustic tagging studies in a marine reserve. Mar. Ecol. Prog. Ser. 262, 253-265.

Parsons D.M., Morrison M.A., McKenzie J.R., Hartill B.W., Bian R., Francis R.C., Hilborn R., 2011, A fisheries perspective of behavioural variability: differences in movement behaviour and extraction rate of an exploited sparid, snapper (Pagrus auratus). Can. J. Fish. Aquat. Sci. 68, 632-642.

Parsons D.M., Morrison M.A., Slater M.J., 2010, Responses to marine reserves: Decreased dispersion of the sparid Pagrus auratus (snapper). Biol. Conserv. 143, 2039-2048.

Pelletier D., Magal P., 1996, Dynamics of a migratory population under different fishing effort allocation schemes in time and space. Can. J. Fish. Aquat. Sci. 53, 1186-1199.

Pelletier D., Mahévas S., 2005, Spatially explicit fisheries simulation models for policy evaluation. Fish Fish. 6, 307-349.

Pelletier D., Mahevas S., Drouineau H., Vermard Y., Thebaud O., Guyader O., Poussin B., 2009, Evaluation of the bioeconomic sustainability of multi-species multi-fleet fisheries under a wide range of policy options using ISIS-Fish. Ecol. Model. 220, 1013-1033.

Polacheck T., 1990, Year around closed areas as a management tool. Nat. Resour. Model. 4, 327-354.
Rademeyer R.A., Butterworth D.S., 2013, 2013 Update of the Reference Set of Operating Models used in testing Candidate OMPs for the South African hake resource. MARAM IWS/DEC13/Hake/P7.

Rademeyer R.A., Butterworth D.S., Plaganyi E.E., 2008, Assessment of the South African hake resource taking its two-species nature into account. Afr. J. Mar. Sci. 30, 263-290.

Rassweiler A., Costello C., Hilborn R., Siegel D.A., 2014, Integrating scientific guidance into marine spatial planning. Proc. R. Soc. B Biol. Sci. 281, 20132252.

Rhodes K.L., Warren-Rhodes K., 2005, Management Options for Fish Spawning Aggregations of Tropical Reef Fishes: A Perspective. Report prepared for the Pacific Island Countries Coastal Marine Program, The Nature Conservancy. TNC Pacific Island Countries Report No. 7/05.

Rice J., Houston K., 2011, Representativity and networks of Marine Protected Areas. Aquat. Conserv. Mar. Freshw. Ecosyst. 21, 649-657.

Rijnsdorp A.D., Van Overzee H.M., Poos J.J., 2012, Ecological and economic trade-offs in the management of mixed fisheries: a case study of spawning closures in flatfish fisheries. Mar. Ecol. Prog. Ser. 447, 179-194.

Roberts C., 2007, The unnatural history of the sea. Washington, DC, Island Press.

Roberts C., 2012, Marine ecology: reserves do have a key role in fisheries. Curr. Biol. 22, R444-R446.

Roberts C., Mason L., 2008, Return to Abundance: A case for Marine Reserves in the North Sea. A report for WWF-UK.

Roberts C.M., Hawkins J.P., Gell F.R., 2005, The role of marine reserves in achieving sustainable fisheries. Philos. Trans. R. Soc. B Biol. Sci. 360, 123-132.

Roberts C.M., Sargant H., 2002, Fishery benefits of fully protected marine reserves: why habitat and behavior are important. Nat. Resour. Model. 15, 487-508.

Rodwell L.D., Roberts C.M., 2004, Fishing and the impact of marine reserves in a variable environment. Can. J. Fish. Aquat. Sci. 61, 2053-2068.

Rooker J.R., Secor D.H., De Metrio G., Schloesser R., Block B.A., Neilson J.D., 2008, Natal homing and connectivity in Atlantic bluefin tuna populations. Science 322, 742-744.

Sadovy de Mitcheson D.M.Y., Cornish A., Domeier M., Colin P.L., Russell M., Lindeman K.C., 2008, A global baseline for spawning aggregations of reef fishes. Conserv. Biol. 22, 1233-1244.

Sadovy Y., Domeier M., 2005, Are aggregation-fisheries sustainable? Reef fish fisheries as a case study. Coral Reefs 24, 254-262.

Sadovy Y., Eklund A.M., 1999, Synopsis of biological data on the Nassau grouper, Epinephelus striatus (Bloch, 1792), and the jewfish, E. itajara (Lichtenstein, 1822). NOAA/National Marine Fisheries Service, Seattle, WA, NOAA Technical Report NMFS.

Sadovy de Mitcheson Y.S.D., Colin P.L., 2012, Reef Fish Spawning Aggregations: Biology, Research and Management. Dordrecht, Springer. Fish and Fisheries Series: Springer, Springer Science + Business Media B.V.

Sale P.F., Cowen R.K., Danilowicz B.S., Jones G.P., Kritzer J.P., Lindeman K.C., Planes S., Polunin N.V., Russ G.R., Sadovy Y.J., et al., 2005, Critical science gaps impede use of no-take fishery reserves. Trends Ecol. Evol. 20, 74-80.

Schaefer K.M., Fuller D.W., 2010, Vertical movements, behavior, and habitat of bigeye tuna (Thunnus obesus) in the equatorial eastern Pacific Ocean, ascertained from archival tag data. Mar. Biol. 157, 2625-2642. 
Schaefer K.M., Fuller D.W., Aldana G., 2014, Movements, behavior, and habitat utilization of yellowfin tuna (Thunnus albacares) in waters surrounding the Revillagigedo Islands Archipelago Biosphere Reserve, Mexico. Fish. Oceanogr. 23, 65-82.

Semmens B.X., Luke K.E., Bush P.G., Pattengill-semmens C., Johnson B., McCoy C., Heppell S., 2006, Investigating the reproductive migration and spatial ecology of Nassau grouper (Epinephelus striatus) on Little Cayman Island using acoustic tags - An Overview. In: Proc. 56th Gulf and Caribbean Fisheries Institute, pp. 1-8.

Sibert J., Hampton J., 2003, Mobility of tropical tunas and the implications for fisheries management. Mar. Policy 27, 87-95.

Sibert J., Senina I., Lehodey P., Hampton J., 2012, Shifting from marine reserves to maritime zoning for conservation of Pacific bigeye tuna (Thunnus obesus). Proc. Natl. Acad. Sci. 109, 18221-18225.

Singleton R.L., Roberts C.M., 2014, The contribution of very large marine protected areas to marine conservation: Giant leaps or smoke and mirrors? Mar. Pollut. Bull. 87, 7-10.

Sink K., Attwood C., 2008, Guidelines for Offshore Marine Protected Areas in South Africa. SANBI Biodiversity Series 9. South African National Biodiversity Institute, Pretoria.

Sladek Nowlis J., Roberts C.M., 1999, Fisheries benefits and optimal design of marine reserves. Fish. Bull. 97, 604-616.

Spalding M.D., Meliane I., Milam A., Fitzgerald C., Hale L.Z., 2013, Protecting marine spaces: global targets and changing approaches. Ocean Yearbook 27, 213-248.

Starr R.M., O'Connell V., Ralston S., 2004, Movements of lingcod (Ophiodon elongatus) in southeast Alaska: potential for increased conservation and yield from marine reserves. Can. J. Fish. Aquat. Sci. 61, 1083-1094.

Stefansson G., Rosenberg A.A., 2005, Combining control measures for more effective management of fisheries under uncertainty: quotas, effort limitation and protected areas. Philos. Trans. R. Soc. B Biol. Sci. 360, 133-146.
Stequert B., Ramcharrum B., 1996, Reproduction of skipjack tuna (Katsuwonus pelamis) from the western Indian Ocean. Aquat. Living Resour. 9, 235-248.

Stockhausen W.T., Lipcius R.N., Hickey B.M., 2000, Joint effects of larval dispersal, population regulation, marine reserve design, and exploitation on production and recruitment in the Caribbean spiny lobster. Bull. Mar. Sci. 66, 957-990.

Tuck G.N., Possingham H.P., 2000, Marine protected areas for spatially structured exploited stocks. Mar. Ecol.-Prog. Ser. 192, 89-101.

Van Keeken O.A., Van Hoppe M., Grift R.E., Rijnsdorp A.D., 2007, Changes in the spatial distribution of North Sea plaice (Pleuronectes platessa) and implications for fisheries management. J. Sea Res. 57, 187-197.

Walters C., 2000, Impacts of dispersal, ecological interactions, and fishing effort dynamics on efficacy of marine protected areas: how large should protected areas be? Bull. Mar. Sci. 66, 745-757.

Walters C.J., Hilborn R., Parrish R., 2007, An equilibrium model for predicting the efficacy of marine protected areas in coastal environments. Can. J. Fish. Aquat. Sci. 64, 1009-1018.

White J.W., Botsford L.W., Baskett M.L., Barnett L.A.., Barr R.J., Hastings A., 2011, Linking models with monitoring data for assessing performance of no-take marine reserves. Front. Ecol. Environ. 9, 390-399.

White J.W., Botsford L.W., Baskett M.L., Barnett L.A.K., Barr R.J., Hastings A., 2011, Linking models with monitoring data for assessing performance of no-take marine reserves. Front. Ecol. Environ. 9, 390-399.

Willis T.J., Millar R.B., Babcock R.C., 2003, Protection of exploited fish in temperate regions: high density and biomass of snapper Pagrus auratus (Sparidae) in northern New Zealand marine reserves. J. Appl. Ecol. 40, 214-227.

Wood L., 2011, Global marine protection targets: How SMART are they? Environ. Manage. 47, 1-11. 